\title{
LA SUSPENSIÓN DE LOS EFECTOS DEL CONVENIO ARBITRAL INTERNACIONAL EN EL MARCO DE LA INSOLVENCIA TRANSFRONTERIZA. UNA REALIDAD Y UN CONFLICTO CADA VEZ MÁS FRECUENTE.
}

\author{
THE SUSPENSION OF THE EFFECTS OF THE INTERNATIONAL \\ ARBITRATION AGREEMENT WITHIN THE SCOPE \\ OF THE CROSS-BORDER INSOLVENCY. A REALITY \\ AND A CONFLICT INCREASINGLY MORE FREQUENT.
}

\author{
María Dolores Martínez Melón \\ Doctora en Derecho. Profesora Asociada de Derecho Internacional Privado \\ Universidad de Cantabria
}

Recibido: 15.01.2010 / Aceptado: 01.07.2020

DOI: https://doi.org/10.20318/cdt.2020.5622

\begin{abstract}
Resumen: Este estudio analiza los puntos de fricción que se producen cuando interactúa un convenio arbitral internacional y un concurso de acreedores al albor de una sentencia dictada recientemente por el Juzgado de lo Mercantil de Santander en incidente concursal y que acuerda la suspensión de los efectos de la referida cláusula arbitral. Se hace un recorrido analítico en busca de la norma de conflicto y selección de ley aplicable para recalar en el análisis del artículo 52.1 de la LC, con una visión crítica de la suspensión judicial acordada, de las posibilidades de nulidad de la cláusula compromisoria y la valoración del perjuicio para el concurso. Finalizamos con la problemática de los efectos extraterritoriales de la sentencia judicial.
\end{abstract}

Palabras clave: insolvencia, convenio arbitral internacional, declaración de concurso, suspensión y nulidad del convenio arbitral, perjuicio concursal.

\begin{abstract}
This study analyses the points of friction that arise as a consequence of the interaction between an international arbitration agreement and an arrangement of creditors in the light of a judgement recently passed by the Commercial Court of Santander during a bankruptcy proceeding and which agrees to suspend the effects of the previously mentioned arbitration clause. An in-depth analysis was carried out to identify the conflict-of-law rule and select the law to be applied, which led to the analysis of the article 52.1 of the LC. The analysis critically evaluated the agreed judicial suspension, the possibilities of nullity of the arbitration clause and the assessment of the negative effects to the arrangement of creditors. Finally, a review of the extraterritorial effects of the judicial sentence is presented.

Keywords: insolvency, international arbitration agreement, declaration of bankruptcy, suspension and nullity of the arbitration agreement, detriment to the arrangement of creditors.

Sumario: I- Introducción. II. El conflicto de la cláusula compromisoria arbitral y la insolvencia desde una perspectiva intracomunitaria. Enfoque general 1. Planteamiento del conflicto. 2. Dificultades de partida en el ámbito internacional. 3. Escenario en el que nos encontramos y enfoques del tratamiento. III. La búsqueda de la norma conflictual en el sistema de insolvencia transfronteriza de la UE, partiendo del asunto DelFuego Booking. 1. Asunto DelFuego Booking, S.L (Concursada)
\end{abstract}


y el artista David Guetta. Planteamiento de la cuestión. 2. La institución del arbitraje comercial internacional en relación con la vis attractiva concursus y el Reglamento (CE) n ${ }^{\circ} 1346 / 2000$, del Consejo, de 29 de mayo de 2000 sobre procedimientos de insolvencia. 3. La innecesaria interpretación sistemática del Reglamento sobre procedimientos de Insolvencia $n^{\circ} 2015 / 848$, de 20 de mayo de 2015. El acogimiento de la vis attractiva concursus. IV. La aplicación de la ley concursal española sobre el convenio arbitral internacional. 1.- De nuevo con la vis attractiva concursus.2.- Tratamiento del arbitraje: sistema monista o dualista. 3.- ¿Puede entonces el juez concursal acordar la nulidad de la cláusula compromisoria con motivo del análisis de la suspensión de los efectos? V. A vueltas con la suspensión del convenio arbitral. Delimitación conceptual. 1.- La suspensión acordada en el asunto DelFuego Booking y David Guetta. 2.- La suspensión de los efectos del convenio: una medida cautelar. VI. El perjuicio para la tramitación del concurso como causa de la suspensión. 1. Valoración judicial del perjuicio en el asunto DelFuego Booking y David Guetta.2. El fraude como causa de anulación de los convenios a tenor de la norma concursal. VII. A modo de cláusula de cierre, y a vueltas con la reverencia que el art. 52.1 in fine hace a los tratados internacionales. 1.Efectos de la resolución judicial acordando la suspensión frente a terceros Estados miembros de la UE. 2. Reconocimiento de los efectos de la resolución suspensiva frente a Estados no miembros de la UE. Una problemática añadida en el asunto DelFuego Booking y David Guetta. VIII. Conclusiones.

\section{Introducción}

1. El recurso por excelencia al arbitraje internacional como solución alternativa a la resolución de conflictos en el ámbito de la contratación internacional, y el inevitable problema de la insolvencia intracomunitaria, previsiblemente más concurrente a tenor de las circunstancias por todos conocidas, la pandemia originada por el virus denominado la Covid-19, han venido provocando, y provocarán, sin duda, situaciones problemáticas y complejas. Las mismas habrán de afrontarse con los recursos jurídicos de los que disponemos lo que no obsta para optar al merecimiento de una respuesta legislativa tanto a nivel nacional como internacional. Consideramos que este hubiera sido un momento óptimo dadas las deficiencias encontradas.

2. La nueva Directiva Europea $\mathrm{n}^{\mathrm{o}}$ 2019/1023 del Parlamento Europeo y del Consejo, de 20 de junio de 2019', en íntima relación con el Reglamento (UE) no 2015/848, de 20 de mayo de 2015², en lo que respecta a la finalidad de promoción de la preconcursalidad, permitiría atenuar parcialmente la inseguridad jurídica que hasta este momento ha venido siendo atajada doctrinal y jurisprudencialmente, entre otros, por el asunto Syska Elecktrim S.A Vivendi Universal S.A $A^{3}$, asunto Pirelli y C.S.P.A $A^{4}$ y recientemente( 2019), por el asunto DelFuego Booking, S.L( Concursada) y el artista David Guetta ${ }^{5}$.

3. Este último asunto será objeto de tratamiento y análisis crítico en el presente trabajo toda vez que la sentencia parte de unos fundamentos jurídicos y jurisprudenciales que en parte entendemos superados, no solo al albor de la normativa posterior que fue dictada en el ámbito nacional e internacional, sino a tenor de la naturaleza de la pretensión instada por la entidad mercantil concursada al juez que declaro el concurso. En todo caso, sentimos la necesidad de un nuevo Reglamento de insolvencia transfronteriza que acoja la armonización de los aspectos esenciales como los que vamos a analizar.

\footnotetext{
${ }^{1}$ Directiva (UE) 2019/1023 del Parlamento Europeo y del Consejo, de 20 de junio de 2019, sobre marcos de reestructuración preventiva, exoneración de deudas e inhabilitaciones, y sobre medidas para aumentar la eficiencia de los procedimientos de reestructuración, insolvencia y exoneración de deudas, y por la que se modifica la Directiva (UE) 2017/1132 (Directiva sobre reestructuración e insolvencia). DOUE» núm. 172, de 26 de junio de 2019.

${ }^{2}$ Reglamento (UE) 2015/848 del Parlamento Europeo y del Consejo de 20 de mayo de 2015 sobre procedimientos de insolvencia (texto refundido) DOUE L 141/19.

${ }^{3}$ Sentencia del Tribunal de Justicia de 2 de octubre de 2008 Syska Elektrim v. Vivendi, High Court of Justice (Queen's Bench Division). (www.bailii.org/ew/cases/EWHC/ Comm/2008/2155.html).

${ }^{4}$ Auto de 29 de abril de 2009 de la Audiencia Provincial de Barcelona (Sección 15a). (EDJ 2009/260256). En España, el asunto Pirelli es el de mayor importancia.

${ }^{5}$ Sentencia del Juzgado de lo Mercantil de Santander, de 30 de septiembre de 2019, Cendoj (EDJ 2019/1003). ECLI: ES: JMS:2019:1003
} 


\section{El conflicto de la cláusula compromisoria arbitral y la insolvencia desde una perspectiva intra- comunitaria. Un enfoque general}

\section{Planteamiento del conflicto}

4. El planteamiento de la controversia obliga a partir del análisis del origen que es claramente de naturaleza conceptual y procedimental. El arbitraje es un mecanismo eminentemente privado de resolución de controversias cuyo régimen jurídico reconoce a las partes amplia autonomía contractual para decidir acerca de su existencia, diseño y funcionamiento. Por su parte, el derecho concursal se asienta en una concepción colectiva y universal del problema que lo desencadena, con una clara finalidad de maximizar las opciones de respuesta a los acreedores en situaciones de insuficiencia patrimonial, a la par que dotar de una nueva oportunidad al concursado, creando y facilitando opciones preventivas de reestructuración, e incluso ofertando posibilidades de exoneración parcial del pasivo al concursado, lo que inevitablemente viene alterando el principio de pacta sunt servanda y las relaciones jurídico- privadas del deudor 6 .

5. La traslación del mentado planteamiento al plano internacional imprime mayor complejidad cuando ambas instituciones interaccionan, ya que pueden darse situaciones en las que una de las partes en un convenio arbitral deviene insolvente, o se encuentre ante un peor escenario, ha sido judicialmente declarada en concurso de acreedores. Este escenario despliega generosas dudas respecto a las posibilidades de coexistencia entre una situación concursal y las obligaciones arbitrales internacionales contraídas?.

\section{Dificultades de partida en el ámbito internacional}

6. Los puntos de fricción relacionados exigen anunciar el primer escollo con el que nos encontramos, el referente a las normas que gobiernan los efectos de un procedimiento de insolvencia sobre el arbitraje internacional, pues ni la Convención sobre reconocimiento y ejecución de sentencias arbitrales extranjeras, hecho en Nueva York el 10 de junio de $1958^{8}$, ni el Convenio europeo sobre arbitraje internacional hecho en Ginebra el 21 de abril de $1961^{9}$, contienen una regulación sobre los aspectos referidos ${ }^{10}$.

7. El segundo gran obstáculo hallado es el referente a que la institución concursal carece actualmente de un tratamiento específico, sistemático y unitario de la materia ${ }^{11}$ tanto en el ámbito nacional como en el internacional, por lo que la búsqueda de la norma de conflicto y selección de ley aplicable se avecina tortuosa atendiendo a si en esa interacción institucional interfiere el derecho internacional privado y, en su caso, si podemos llegar a identificar la ley o la norma que debe ser empleada para analizar

\footnotetext{
${ }^{6}$ Sobre los principios, vid. A. Rojo, "El Derecho concursal”, en R. Uría / A. Menéndez, Curso de Derecho Mercantil II, $2^{\mathrm{a}}$ Ed., Civitas, Madrid, 2007, pp. 900-901.

${ }^{7}$ Sobre la regulación del arbitraje en la Ley Concursal vid., entre otros, E. VERDERA Y TuELLs, "Reflexiones preeliminares sobre el arbitraje en la Ley Concursal", en: Estudios sobre la Ley Concursal. Libro Homenaje a Manuel Olivencia, Marcial Pons, Madrid, 2005, pp. 3295-3354; P. Perales Viscasillas, "Los efectos del concurso sobre los convenios arbitrales en la Ley Concursal 22/2203 (I y II)”, Diario La Ley, Núms. 6035 y 6036, 8 y 9 de junio de 2004.

${ }^{8}$ Convención de Nueva York sobre el reconocimiento y la ejecución de las sentencias arbitrales extranjeras, hecho en Nueva York el 10 junio 1958 (BOE núm. 164, 11 julio 1977). .

${ }^{9}$ Convenio europeo sobre arbitraje comercial internacional, hecho en Ginebra, el 21 abril 1961 (BOE núm. 238, 4 octubre 1961)

${ }^{10}$ Sobre ambos instrumentos jurídicos internacionales vid. M. Gómez Jene, El arbitraje comercial internacional en la Unión Europea: la eficacia del laudo arbitral, Colex, Madrid,2000, pp. 34-90.

${ }^{11}$ En el ámbito nacional ha habido grandes reformas, hasta 28 se han contabilizado desde que fue aprobada la Ley concursal por ley 22/2003, de 9 de julio, BOE núm. 164 de 10 de julio de 2003.

En reciente Texto refundido de fecha 6 de mayo de 2020 se ha codificado la normativa concursal, BOE número.127, de 7 de mayo de 2020.
} 
la "eficacia" del convenio arbitral internacional una vez haya sido declarado el concurso de acreedores, ya sea este de carácter nacional o transfronterizo.

\section{Escenario en el que nos encontramos y enfoques del tratamiento}

8. Nos encontramos ante un escenario, el concursal y el arbitral, con numerosa doctrina y precedentes judiciales que apelan a la naturaleza de cada institución como forma de acaparar protagonismo, con diferentes regímenes de Derecho internacional privado y una lógica conflictual diferente que debiera llevarnos a un mismo resultado.

9. El enfoque del tratamiento obliga a partir de la ley concursal española toda vez que en el asunto objeto del objeto de análisis, DelFuego Booking y David Guetta, se solicita por la entidad concursada la suspensión de los efectos del convenio arbitral internacional una vez ha sido declarado el concurso de acreedores en territorio español, de conformidad con el artículo 52.1 LC.

10. El artículo 52.1 LC establece dos premisas fundamentales en cada uno de los apartados que lo componen de las que necesariamente hemos de partir. El primero proclama que la declaración de concurso no implica, por si sola, que los pactos de mediación y los convenios arbitrales suscritos por el concursado queden afectados. No obstante, refiere el precepto que podrán suspenderse por el juez los efectos de tales actos si considera que pueden suponer un perjuicio para la tramitación del concurso. En el apartado 2, el precepto, y sin ambages, garantiza el respeto a la cláusula compromisoria cuando a la fecha de la declaración del concurso de acreedores el procedimiento arbitral ya esté en tramitación.

11. El artículo 52 LC fue objeto de modificación por ley 11/2011, de 20 de mayo, de Arbitraje, con la finalidad de adaptarse a las soluciones comunitarias en la materia, pasando de una regulación contraria a mantener la vigencia de los convenios arbitrales antes de la declaración de concurso a una posición pro convenio arbitral. Esta modificación resulta esencial a los efectos que nos ocupan pues el espíritu de la reforma no solo nos ha de guiar en la búsqueda de la norma de conflicto y selección de ley aplicable, sino también en el hecho, no menos importante, de que los precedentes judiciales, asunto Syska Elektrim S.A y Vivendi Universal S.A, y asunto Pirelli y C.S.P.A, anteriores ambos a la reforma, pueden no resultar de útil aplicación, como vienen, sin embargo desoyendo gran parte de la resoluciones que se dictan, entre ellas la del asunto DelFuego Booking y David Guetta, como también lo hace la mayoría de la doctrina con motivo de los diferentes comentarios efectuados a las referidas resoluciones.

12. Luego, si el espíritu de la reforma concursal por Ley de arbitraje el 20 de mayo 2011 lleva inherente una protección de los convenios arbitrales dentro del procedimiento concursal, reforma que también se produjo en el ámbito comunitario, de la que aquella trae causa, lo que vino a ocasionar fue la quiebra de la respuesta normativa dada hasta ese momento.

13. También se produce un nuevo silogismo que es obviado por la mayoría de la doctrina y la jurisprudencia citada, como abordaremos en este trabajo, el referente al acto o resolución suspensiva que excepcionalmente puede acordar el juez concursal de los efectos de la cláusula compromisoria a tenor del art. 52.1 LC. Considero que la suspensión y su tratamiento no debe confundirse con la validez del convenio arbitral. Cometer ese error no solo nos lleva a una valoración del perjuicio para la tramitación del concurso diametralmente opuesta, sino que en la búsqueda de la norma de conflicto partimos de un nuevo error de calificación.

14. El enfoque del tratamiento anunciado no debe pasar por alto la última de las consideraciones prácticamente unánimes de la doctrina, a la que sigue la jurisprudencia consultada, y con la que estoy en manifiesto desacuerdo, la referente a la alusión que el artículo 52.1 LC hace a los tratados internacionales. No asumo que nos encontremos ante una referencia impertinente por inútil porque a la postre viene 
a permitir al juzgador que pueda abordar en vía incidental, y si existen razones fácticas y jurídicas para ello, la nulidad del convenio arbitral, aplicando, ahora sí, los convenios de Nueva York y Ginebra que regulan la referida materia.

15. A tenor de lo anteriormente expuesto, si la norma de conflicto que resulta de aplicación, que ya adelantamos se trata del Reglamento (UE) del Parlamento Europeo y del Consejo sobre procedimientos de Insolvencia 2015/ 848, de 20 de mayo de $2015^{12}$, recala ante el juez que acordó la apertura del procedimiento concursal, en nuestro caso el juez de lo mercantil número 1 de los de Santander, entendemos que muchas de las argumentaciones son innecesarias, y unas pocas, no por ello menos importantes, son erráticas.

16. En este este estado de la cuestión, anunciamos como metodología de trabajo la siguiente: expondremos los datos fácticos y jurídicos y los criterios de búsqueda de la norma de conflicto por parte del juez concursal en el asunto DelFuego Booking y David Guetta, algunos de los cuales compartimos, entre otras, la inevitable interpretación sistemática de los Reglamentos de insolvencia comunitarios, para pasar a centrarnos en el análisis de nuestro derecho concursa ${ }^{13}$, especialmente en el análisis del artículo 52, apartado 1 de la ley concursal ( LC) ${ }^{14}$.

17. Serán objeto de tratamiento los aspectos críticos apreciados en la sentencia judicial, mostrando especial atención en el sentido y efectos que el juez otorga a la posibilidad de la suspensión de los efectos de la cláusula, toda vez que decreta de forma tácita la nulidad, cuando por prescripción legal lo que debe acordar es una medida cautelar de suspensión de los efectos con la posibilidad de ser alzados.

El haber adoptado referida resolución ha implicado que el perjuicio que la sustenta se base en un manejo de parámetros diferentes a los que exige la suspensión como medida cautelar y lo que es más gravoso, que permita aflorar las normas de competencia judicial internacional cuando lo que procede es suspender la posibilidad de acudir a la vía arbitral hasta en tanto en cuanto no se alce la medida acordada.

18. Defendemos igualmente, y en su momento argumentaremos que, si judicialmente se opta por acordar la suspensión de los efectos de la cláusula compromisoria suscrita, los efectos inherentes difieren de los que permite la declaración de nulidad. Dicha nulidad puede acordarse por el juez concursal, en vía incidental, pero para ello debe valorar las causas que la sugieren a tenor de los tratados internacionales a los que alude el art. 52, in fine de la LC. En esta misma línea defendemos como tercera opción que el juez concursal también está legitimado para abordar la existencia de un posible fraude en la inserción de la cláusula compromisoria si ve méritos para ello, pero esta vez la legitimación se la concede el art. 53 LC. Veremos que no se ha adoptado ninguna de las opciones propuestas en el asunto DelFuego Booking y David Guetta pese a que el juzgador concursal las tenía a su alcance.

\section{La búsqueda de la norma conflictual en el sistema de insolvencia transfronteriza de la UE, partiendo del asunto DelFuego Booking y David Guetta}

19. Planteado el conflicto en los términos expuestos, es decir, cuando confluye una cláusula arbitral que está inerte al momento en que uno de los suscribientes de la misma ha sido declarado en concurso, hemos de anunciar que han sido criterios jurisprudenciales los que sucesivamente en el tiempo

${ }^{12}$ DOUE L 141/19, de 5 junio 2015 (RI bis). Reglamento que vino a refundir el Reglamento (CE) núm. 1346/2000 del Consejo, de 29 de mayo de 2000, sobre procedimientos de insolvencia DOUE L 160, de 30 junio 2000. Ambos reglamentos no son aplicables en Dinamarca.

${ }^{13}$ Son numerosos los trabajos que se han encontrado sobre este precepto, pero consideramos uno especialmente importante, que incluso ha sido referenciado en la sentencia del asunto DelFuego Booking y David Guetta, M.A. PenEdÉs Fons, Insolvencia Transfronteriza y Arbitraje comercial internacional (Tesis doctoral), Universidad de Valencia, 2015.

${ }^{14}$ Valoraremos la nueva redacción del precepto a tenor de la reciente promulgación del Texto Refundido de la Ley Concursal de fecha 6 de mayo de 2020, BOE 7 de mayo de 2020, que entrará en vigor el día 1 de septiembre de 2020. 
han ido asumiendo la labor de búsqueda de la norma de conflicto para dar una respuesta judicial puntual a las controversias planteadas toda vez que ni los Reglamentos comunitarios ni los tratados en vigor daban una puntual respuesta. En el asunto DelFuego Booking y David Guetta se ha partido de la referida jurisprudencia y en especial de los asuntos Elektrim y Pirelli a sabiendas de que cada uno de los asuntos partían de datos fácticos y anunciaban matices diferentes ${ }^{15}$.

20. La razón por la que hemos elegido el análisis del asunto DelFuego Booking y David Guetta y no otro, se debe a que la norma de conflicto susceptible de ser aplicada es el Reglamento 2015/848 y no su predecesor, lo que nos permite no solo romper con los criterios sentados por los paradigmáticos asuntos referenciados y ahondar en unos nuevos, sino también dar una respuesta innovadora a una generalidad de cuestiones de gran calado práctico, es decir, a la relación de conflicto que existe entre una cláusula arbitral internacional que no ha sido activada y la situación de insolvencia que ha sido declarada judicialmente respecto a una de las partes y en territorio español, y que nos lleva a aplicar el art. 52.1, reformado por ley 20/2011, de 20 de mayo de Arbitraje, que a su vez viene a romper moldes respecto a la normativa y criterios jurisprudenciales seguidos hasta ahora.

Ello nos obliga a reformular de nuevo una serie de preguntas: ¿derogan las reglas concursales todos los efectos de una cláusula arbitral pese a estar inactiva? ¿o sobreviven y en qué medida, a los efectos de un procedimiento de insolvencia?, ¿quién goza de mayor protección, la institución arbitral o la concursal? ${ }^{16}$

21. Ha de darse debida respuesta a cada una de las cuestiones pues ya no pueden ser los asuntos Elektrim y Pirelli los que sienten precedente, como así parece sugerir la sentencia del asunto DelFuego Booking y David Guetta. Es cuestión de tiempo que pronunciamientos sobre conflictos similares se produzcan y es más que previsible también que el sentido de la decisión sea distinto en cada uno de ellos. Es una materia plagada de incertidumbres que debe ser, como ya se ha adelantado, debidamente regulada, aunque a corto plazo nos mostremos pesimistas ${ }^{17}$. Pese a ello, creo dar debida respuesta a las cuestiones planteadas en este trabajo.

\section{Asunto DelFuego Booking, S.L(Concursada) y el artista David Guetta. Planteamiento de la cues- tión}

22. El supuesto de hecho de la sentencia que vamos a diseccionar se ha dictado por el Juzgado de lo Mercantil $\mathrm{n}^{\circ} 1$ de Santander en fecha 30 de septiembre de 2019. El relato fáctico se centra en el

\footnotetext{
15 Tanto en el asunto Elecktrim contra Vivendi como en el asunto Pirelli contra la sociedad española LP, se ha efectuado un análisis sistemático de la aplicación del Reglamento de insolvencia núm. 1346/2000 por ser el que se hallaba en vigor y a los efectos de localizar la norma de conflicto y selección de ley aplicable. Ya en este último asunto, similar al que analizaremos, encontrada la norma de conflicto, y declarado en España el concurso de acreedores de la sociedad española, el juez se esmera en el análisis del art. 52.1 de la LC, en su redacción antes de la reforma del precepto por la ley de arbitraje.

${ }^{\text {Son }}$ similares las pautas interpretativas en el asunto Elektrim contra Vivendi con la finalidad de llegar a la localización de la norma de conflicto y selección de ley aplicable, que le aboca al análisis del derecho internacional privado polaco, art. 142 por ser el país en el que se declaró el concurso de Elektrim y en virtud del cual se dejó sin efectos la cláusula arbitral formalizada entre ambas entidades para solventar sus controversias y que sometían al arbitraje en Londres y de acuerdo con las normas de la London Court of Internacional arbitration, No obstante en este asunto, a diferencia del asunto Pirelli y Delfuego Booking el procedimiento arbitral comenzó antes que el procedimiento concursal, lo que veremos es significativo.

${ }^{16}$ Reparemos que la cláusula compromisoria tiene naturaleza contractual independiente del contrato en la que se inserta. También disfrutan de esa naturaleza los pactos de mediación, así como los diferentes contratos que unen a la parte concursada con terceros y que en virtud de las obligaciones contraídas han devengado un crédito que pretenden cobrar en el oportuno concurso de acreedores.

${ }^{17}$ La Directiva europea 2019/1023, es una Directiva de mínimos y respecto a los marcos de reestructuración preventiva y exoneración de deuda con un plazo de transposición largo y que pese a la pretendida coordinación con el Texto Refundido de la Ley concursal este ha visto su luz antes de lo deseado por lo que auguramos nuevas reformas de la Ley Concursal a corto y medio plazo.
} 
siguiente objeto y planteamiento de la solicitud ${ }^{18}$ : la concursada, Delfuego Booking S.L, firmó el 27 de abril de 2018, un contrato con los agentes representantes del artista David Pierre Guetta, Creative Artists Agency, Talent Management \& Servicies FZ-LLC, cuyo objeto era prestar los servicios, y por ende, la actuación del artista, de reconocida fama mundial.

23. En la condición adicional 18 del precitado contrato, sobre ley aplicable y jurisdicción, se indica que la ley aplicable al contrato será la de Inglaterra y Gales, y que cualquier disputa se resolverá mediante arbitraje con Sede en Londres, siendo el idioma a emplear el inglés (no se aportan más especificaciones relativas al arbitraje).

24. Se da el caso que el artista no compareció a la actuación contratada y procedió a devolver parte de su caché (203.000 euros), si bien la promotora pretende reclamar el resto del caché, gastos directos e indirectos sufridos, y daños y perjuicios, aventurando una reclamación superior a los 600.000 euros.

25. Entiende la concursada que el convenio arbitral en cuestión causaría graves perjuicios para "el concurso y su tramitación", para ello se apoya en dos razones (según refiere la sentencia): la primera, la incertidumbre de la cláusula pues no se indica árbitro ni colegio o administrador ni reglamentación bajo la que el arbitraje se desarrollaría, lo que impactaría en una enorme dilación en la propia y simple constitución del arbitraje, además de una incertidumbre insalvable para el concurso, que en otro caso podría allegar sumas relevantes ( en caso de tener éxito en su reclamación) para la masa concursal; la segunda, los costes de administración de arbitraje, honorarios de árbitros y letrados especializados con sede en Londres serían inasumible por la masa del concurso.

26. El planteamiento jurídico del solicitante, el concursado, se apoya en la naturaleza contractual del convenio arbitral y en su carácter internacional para, por la vía del art. 7.2 e) del Reglamento (UE) 2015 / 848 del Parlamento Europeo y del Consejo de 20 de mayo de 2015 sobre procedimientos de insolvencia, llegar a la aplicación de la norma nacional española, como lex foris concursus, que en su art. 52.1 de la Ley Concursal permite la suspensión del convenio arbitral con ciertas condiciones.

Es de recibo destacar que el artista no compareció en el incidente concursal que se abrió en el procedimiento concursal para conocer de la solicitud de suspensión por lo que se declaró su rebeldía procesal, motivo por el cual no contamos con alegaciones a la pretensión de la concursada; aunque nos consta que el artista ha efectuado recurso de apelación frente a la sentencia ante la Audiencia Provincial de Cantabria ${ }^{19}$.

\section{La institución del arbitraje comercial internacional en relación con la vis attractiva concursus y el Reglamento (CE) $n^{0}$ 1346/2000, del Consejo de 29 de mayo de 2000 sobre procedimientos de insolvencia}

27. Pese a que, tal y como hemos referido, nuestro objeto de estudio se va a centrar en el análisis de la cláusula arbitral inactiva a la fecha de declaración del concurso de acreedores y la suerte de suspensión de sus efectos después de las reformas comunitarias y nacionales a las que hemos hecho alusión, es ineludible hacer referencia al mentado tratamiento de la institución dentro del Reglamento de Insolvencia transfronteriza predecesor al vigente porque de esta manera desmontaremos la opinión doctrinal y judicial de la forma en que actualmente se ha de localizar la norma de conflicto y la selección de ley aplicable por el juez nacional que ha acordado la apertura del concurso.

28. Es un hecho no discutible, por notorio, y sumamente importante, que los instrumentos internacionales por excelencia y susceptibles de aplicación, el Convenio europeo de Ginebra de 1961

\footnotetext{
${ }^{18}$ En la exposición de hechos hemos respetado casi la literalidad con la que se pronuncia la sentencia, al obviar lo que puede resultar inútil a los efectos pretendidos.

${ }^{19}$ Hecho conocido por los periódicos de tirada provincial.
} 
sobre arbitraje comercial internacional y la Convención de Nueva York de 1958 sobre reconocimiento y ejecución de sentencias arbitrales extranjeras, nada refieren en cuanto a los efectos que una posible situación de insolvencia puede tener sobre el compromiso arbitral, ni de selección de ley aplicable. El primero de ellos se emplea principalmente en regular la eficacia de los convenios arbitrales de modo que solo los tribunales arbitrales acepten la competencia para conocer sobre el fondo del asunto cuando exista un convenio válido.

29. Sin embargo, es la Convención de Nueva York la que realmente constituye la esencia del arbitraje comercial internacional pues se centra en el reconocimiento y ejecución de laudos extranjeros, prácticamente a nivel mundial ${ }^{20}$. En un grado descendente, pero no por ello menos importante, tenemos las leyes nacionales, en nuestro caso la Ley 60/2003, de 23 de diciembre, de Arbitraje, que regula la actividad arbitral que se desarrolla en el territorio de cada Estado; en todo caso es de aplicación supletoria cuando los instrumentos internacionales de aplicación no regulan nada al respecto. En lo que nos compete la ley de arbitraje nada refiere en cuanto los efectos de la interrelación jurídica entre el arbitraje y la insolvencia ${ }^{21}$.

30. Asumido cuanto hemos expuesto no es baladí sentar que el Reglamento de insolvencia $\mathrm{n}^{\circ} 1346 / 2000$, de 29 de mayo de 2000, guardaba un meridiano silencio sobre las expresas acciones que se pueden ejercitar y derivarse del procedimiento de insolvencia o bien, que guardaren relación con ella ${ }^{22}$.

31. Un regulación deficiente del Reglamento de insolvencia en el sentido expuesto colocaba al juez ante dos cuestiones francamente problemáticas: la primera, la referente a si las calificaciones efectuadas a tenor de la normativa interna nacional son, o no son, las más adecuadas para determinar la ley aplicable ${ }^{23}$; y en segundo lugar, en qué medida el principio de vis attractiva concursus, y en su concepción europea, venía a interferir en el ámbito competencial al auspicio del Reglamento de insolvencia y del Reglamento de la UE $n^{\circ}$ 1215/ 2012 de 12 diciembre de 2012, relativo a la competencia judicial, el reconocimiento y la ejecución de resoluciones judiciales en materia civil y mercantil ${ }^{24}$.

32. Esa deficiencia del Reglamento 1346/2000 en cuanto a la delimitación de las acciones que caen bajo el auspicio de su competencia permitía concluir con la idea de que no era posible interpretar correctamente las normas sobre ley aplicable previstas por el Reglamento de insolvencia sin tener presente el régimen de competencia judicial internacional y el principio de vis attractiva concursus diseñado por el legislador de la Unión ${ }^{25}$. Únicamente tras explorar estos dos aspectos era posible efectuar

${ }^{20}$ La convención de Nueva York tiene el don de la universalidad toda vez que 163 países son los que a la fecha lo han ratificado. https://uncitral.un.org/es/texts/arbitration/conventions/foreign_arbitral_awards/status2o. Para profundizar vid. M. VIRGós Soriano, "Arbitraje Comercial Internacional y Convenio de Nueva York de 1958”, en Actualidad Jurídica Uría Menéndez, número extraordinario (Homenaje al profesor D. Rodrigo Uría González en el centenario de su nacimiento), 2006, p. 25.

${ }^{21}$ No obstante, se volverá sobre ellos por lo que luego se dirá.

${ }^{22}$ El Reglamento es el instrumento diseñado por la Unión Europea para regular los aspectos internacionales de los procedimientos concursales abiertos en los Estados Miembros y contiene principalmente reglas de Derecho internacional privado. El reglamento se asienta sobre el principio de unidad legal, según el cual el estado de apertura (la lex foris concursus) será aplicable a todo el procedimiento de insolvencia y determinará todos los efectos del procedimiento de insolvencia, tanto procesales como materiales, pues parte del principio de que el concurso es uno y cuya resolución de apertura ha de reconocerse por todos los Estados de la Unión así como todos los efectos que la legislación de ese país produzcan. En este sentido opina M. A. PENEDÉS Fons, op cit, p. 15, quien a su vez refiere que así lo declara tanto la opinión de la AG Kokott como la Sentencia del TJUE en el Asunto C.294/02, Comisión Europea v AMI Semiconductor Belgium BVBA [2005] Rec. I-2175, párs. 84 y 69 respectivamente.

${ }^{23}$ Un problema de calificación se produjo en el asunto Elektrim como veremos. Además de constituir el primer estudio judicial de la cuestión, este pronunciamiento se ha convertido en la máxima autoridad jurisprudencial en la UE, motivo por el cual ha tenido mucho que ver en el Reglamento de insolvencia 2015/848.

${ }^{24}$ DOUE L 135/1, de 20 de diciembre de 2012, conforme a su artículo 81 será aplicable a partir de 10 de enero de 2015.

${ }^{25}$ M.A. Penedés Fons, op cit, p 41. Vid. L. Carballo Piñeiro, "Vis attractiva concursus in the European Union: its development by the European Court of Justice", Revista para el análisis del Derecho, 2010. Disponible en:https://indret.com/ wp-content/themes/indret/pdf/750_es.pdf,( último acceso a 28/05/2020)

En el resumen de la obra establece que: a diferencia de los precedentes proyectos de Convención sobre procedimientos de insol- 
una interpretación congruente acerca de la influencia que tiene el Reglamento de procedimientos de insolvencia sobre el arbitraje internacional.

33. Ese vaivén de interpretaciones efectuadas a golpe de casuística con la finalidad de limitar lo que era competencia del Reglamento de insolvencia y respecto a las materias excluidas del Reglamento Bruselas I Bis ${ }^{26}$ - el concurso y el arbitraje- permiten pensar en que los Estados tendrán que recurrir a regímenes de atribución de competencia, ya sean de naturaleza convencional o interna, cuando se apliquen regímenes distintos al Reglamento Bruselas I Bis, y por tanto, el juez concursal podrá centrar la atención en el derecho nacional y la concepción que cada ordenamiento jurídico tenga de la vis attractiva concursus. Sostiene Virgós y GARCIMARTín que esta es una disputa excluida tanto del art. 3 como del 25.II del Reglamento de insolvencia ${ }^{27}$, y por ende el recurso a otros regímenes no entrará en contradicción con las normas del Reglamento de Insolvencia. La misma consideración ha de hacerse del arbitraje, en tanto que es una materia descartada del Reglamento de Bruselas I Bis y por ende ha de acudirse a la normativa nacional ${ }^{28}$.

34. Para la totalidad de la doctrina en esa búsqueda de la norma de conflicto y selección de ley aplicable, era sumamente importante la naturaleza jurídica de los convenios arbitrales. La opinión mayoritaria cedía ante la naturaleza contractual del convenio, incluidos los pactos de mediación, y por ende será la lex fori concursus, de acuerdo con su ley nacional, la que determinará el efecto que la apertura del procedimiento de insolvencia producirá sobre la validez y eficacia de la cláusula por el que las partes, una de ellas concursada, han sometido las controversias de una determinada relación contractual a arbitraje ${ }^{29}$.

\section{La innecesaria interpretación sistemática del Reglamento sobre procedimientos de Insolvencia 2015/848, de 20 de mayo de 2015. El acogimiento de la vis attractiva concursus}

35. Como punto de partida ha de señalarse que el Reglamento 2015/848, es plenamente aplicable a la situación que nos concierne, asunto Delfuego booking y David Guetta, que es, a todas luces, un supuesto intracomunitario de insolvencia -las partes están domiciliadas en Francia y España y, además, la sede designada para el arbitraje está en Londres, a la fecha de formalización de la cláusula compromisoria, aunque actualmente Reino Unido es un Estado no miembro de la Unión Europea ${ }^{30}$.

vencia, el Reglamento (CE) número 1346/2000 no establece una regla especifica sobre vis attractive concursus a pesar de que el Tribunal de Justicia de las Comunidades Europeas ya había sostenido en el caso Gourdain c. Nadler que las acciones que derivan directamente de la insolvencia y guardan una inmediata relación con el concurso no están incluidas en el ámbito de aplicación de la Convención de Bruselas. El silencio del Reglamento de insolvencia y el hecho de que las acciones mencionadas estuvieran excluidas de la Convención de Bruselas, ahora Reglamento Bruselas I, motivaron diversas interpretaciones, a las que ahora ha puesto término el Alto Tribunal al establecer en Seagon c. Deko Marty Belgium que el artículo 3 del Reglamento de insolvencia contiene el principio de vis attractiva. Ahondando en esta dirección, esta decisión ha ido inmediatamente seguida por otras dos, SCT Industri c. Alpenblume, y German Graphics c. A. van der Schee, con el mismo telón de fondo, esto es, determinar qué acciones están incluidas en el ámbito de aplicación del Reglamento núm. 1346/2000 y, por tanto, han de ser atraídas ante el forum concursus

${ }^{26}$ Algunos autores como M. Gómez Jene, "Concurso y arbitraje internacional" (2010) 2(2) Cuadernos de Derecho Transnacional, vol. 2, núm 2, pp. 92, 98 como la versión final del art. 4.2.f) RI (es decir, el nuevo art. 7.2.f) RI bis) 15 RI (que pasa a ser el art. 18 RI bis) refieren que no supone ninguna aportación sustantiva a la opinión de los estudios en la materia, que ya desde hace años han alcanzado un sólido consenso respecto a la inclusión del arbitraje en los arts. 4.2.f) y 15 RI predecesor al actual, al calificar al convenio como un mero contrato, p. 100.

${ }_{27}$ M. Virgós Soriano y F. Garcimartín Alférez, Comentario al Reglamento Europeo de Insolvencia, Civitas, Madrid, 2003, p. 66.

${ }^{28}$ En concreto, el art. 3. RI 1346/2000, preveía la posibilidad de que se abran procedimientos secundarios en todos aquellos Estados en los que el deudor tenga un establecimiento, quedando sus efectos limitados a los bienes sitos en ese territorio; el art. 25 RI parece sugerir que pueden existir acciones individuales que involucren al deudor concursal fuera del procedimiento de insolvencia.

${ }^{29}$ Ibidem, pp.79 y 80, el autor lo razona trayendo a colación el criterio jurisprudencial y doctrinal (en especial el del profesor Heredia).

${ }^{30}$ Poca o ninguna duda cabe con respecto a la naturaleza concursal del convenio arbitral. Sobre esta cuestión conviene hacer referencia nuevamente a las apreciaciones sobre la naturaleza de la cláusula, ya vista como un mero contrato o como un contrato procesal, efectuadas por M. Gómez JENEE," Concurso y Arbitraje...” op cit. pp. 100-101. 
36. Tanto el Reglamento 2015/848 como su predecesor señalan, en sus arts. 7 y 4 , respectivamente, que la ley aplicable a los procedimientos de insolvencia será la del Estado miembro en el que se abra cada uno de ellos. Según el enunciado, la ley aplicable señalada vendrá a determinar las condiciones de apertura, desarrollo y conclusión del procedimiento, además de, en especial, los efectos del procedimiento de insolvencia sobre los contratos vigentes en los que el deudor sea parte-art. 4.2.e) de la versión antigua y 7.2.e) de la moderna-.

37. El Reglamento Europeo sobre procedimientos de Insolvencia 1346/2000, de 29 de mayo, tal y como ya hemos avanzado, no contenía regulación alguna relativa a la vis attractiva ${ }^{31}$, por lo que necesariamente había de acudirse a la noción que de ella tenían los derechos nacionales. De la misma manera, el considerar que los convenios arbitrales disfrutan de la naturaleza contractual, facilitaba la labor de búsqueda porque permiten someterlos al régimen conflictual previsto en el Reglamento de insolvencia para los contratos.

38. Todo cuanto se ha expuesto tiene suma importancia toda vez que el Reglamento vigente difiere sustancialmente del anterior, por lo que la interpretación sistemática que anteriormente se exigía, y así quedó plasmado en el asunto Elektrim y Pierelli, ya no se precisa bajo las previsiones legales contenidas en el actual Reglamento 2015/848. Sin embargo, tanto la sentencia del asunto DelFuego Booking y David Guetta como la doctrina insisten en acudir a ella ${ }^{32}$.

39. El Reglamento $2015 / 848$, ha respetado una amplia percepción del principio de vis atractiva concursus y una primacía del Reglamento de los procedimientos de insolvencia en la regulación de los asuntos que pertenezcan a la materia propiamente concursal, como ocurre con el analizado ${ }^{33}$, pero lo que es sumamente importante, le dedica una expresa protección al arbitraje en al artículo $18^{34}$, lo que delimita la suerte del convenio arbitral que se halle inerte a la fecha de declaración del concurso, y lo que no es menos importante, acoge verdaderas normas de competencia judicial internacional en la que, sin esfuerzo, podemos incluir la que es objeto de análisis al albor del asunto de referencia, es decir la suerte de paralización de una clausula arbitral susceptible de ser activada.

40. Merece la pena insistir en que el Reglamento 2015/848 introdujo una importante novedad con respecto a su antecesor que localizamos en su artículo 18, que, bajo el revelador título de efectos del procedimiento de insolvencia sobre procesos en curso o procedimientos arbitrales en curso, enuncia lo siguiente:

Los efectos del procedimiento de insolvencia sobre procesos en curso o procedimientos arbitrales en curso en relación con un bien o un derecho que formen parte de la masa del deudor se regirán exclusivamente por la ley del Estado miembro en el que esté en curso dicho proceso o en el que tenga su sede el tribunal arbitral.

${ }^{31}$ Es muy explicativo M. Gómez Jene, Concurso y arbitraje..., op cit. p. 99., pues analiza como una de las características generales del Reglamento europeo de insolvencia la no vis attractiva concursus.

${ }^{32}$ Sobre el comentario de esta sentencia vid. a I. Heredia Cervantes, “Arbitraje, concurso internacional y ... David Guetta y "El Problema: la eficacia en un concurso internacional de un convenio arbitral concluido por el deudor antes de la declaración de apertura", Almacen de Derecho. https://almacendederecho.org/arbitraje-concurso-internacional-y-david-guetta ( última consulta 10 de junio de 2020)

${ }^{33}$ Vid. el considerando 66 del Reglamento 2015/848 en el que se acoge una clara primacía:”... La lex concursus determina todos los efectos del procedimiento de insolvencia, tanto procesales como materiales, sobre las personas y las relaciones jurídicas implicadas. Regula todas las condiciones para la apertura, desarrollo y conclusión del procedimiento de insolvencia".

Más sobre esto lo analiza E. Torralba Mendiola, "Las insolvencias transfronterizas en la Unión Europea: perspectivas jurisprudenciales y retos", Cuadernos de Derecho Transnacional,2019, vol. 11, nº 2, pp. 360-383.

${ }^{34} \mathrm{La}$ redacción del antiguo articulo 15 solo mencionaba "los procedimientos en curso" sin aludir a los procedimientos arbitrales. 
41. En sintonía con lo anterior se puede apreciar que el nuevo Reglamento de procedimientos de insolvencia, al igual que la ley concursal en su art. 52, reformado en el año 2011 por la Ley de Arbitraje y el art. 140 del Texto Refundido de la LC, otorga un tratamiento distinto al convenio arbitral y al arbitraje, siendo así que las leyes aplicables son distintas para el caso en que la declaración de concurso sea previa o no a la suscripción del acuerdo o a la iniciación del arbitraje. Así, si un arbitraje se inicia antes de la declaración de concurso, se procederá a aplicar, y a la luz del nuevo Reglamento, la lex loci arbitri. En cambio, si el arbitraje se inicia tras la declaración del concurso, se aplicará la lex fori concursus.

42. Reiteramos nuevamente que la interpretación efectuada por el juzgador es del todo innecesaria a tenor de la importancia que también adquiere la dicción legal del artículo 6 del Reglamento de procedimientos de insolvencia $2015 / 848$, pues a la postre viene a consagrar normativamente el principio de la vis attractiva concursus europea ${ }^{35}$, que fue acogida por la jurisprudencia, completándose así el largo proceso que generaron grandes interrogantes y que fueron salvados por el criterio Gourdain ${ }^{36}$ y que además vino a clarificar el régimen competencial internacional de acciones civiles y mercantiles en escenarios concursales, poniendo coto y solución al problema de calificación y a las fisuras existentes entre el Reglamento de Insolvencia predecesor al vigente y el Reglamento Bruselas I bis. ${ }^{37}$

43. En conclusión, el Reglamento de insolvencia vigente no cambia las reglas de competencia de aquellos litigios que se pudieran haber planteado con independencia del concurso, pero sí las que estén ligadas y entrelazadas con él, como sucede con la suspensión de la cláusula compromisoria, o por ejemplo, entre otras que vamos a tratar, la nulidad de la cláusula compromisoria por el juez concursal en vía incidental o la impugnación de la misma por fraudulenta.

44. La legitimación competencial para entender que el juez concursal puede asumir el conocimiento de la acción de nulidad o impugnación por fraude del convenio arbitral viene de la mano del artículo 6 del Reglamento 2015/848 que, como ya hemos referido, acoge verdaderas normas de competencia judicial internacional, así lo sugiere cuando se titula: "Competencia para las acciones que se deriven directamente de los procedimientos de insolvencia o guarden una estrecha vinculación con ellos". Establece el apartado 1 del referido artículo: "Los órganos jurisdicciones de un estado miembro en cuyo territorio se haya abierto un procedimiento de insolvencia en aplicación del art. 3 serán competentes para cualquier acción que se derive directamente del procedimiento de insolvencia y guarde una estrecha vinculación con este, como las acciones revocatorias" ${ }^{\prime 38}$.

${ }^{35}$ Un buen análisis sobre esto, a tenor de la STJUE 9 noviembre de 2017, Tünkers, EU:C:2017:847, sobre los límites de la vis attractiva de la competencia judicial internacional de los tribunales del Estado de apertura de un procedimiento de insolvencia en aplicación del artículo 3 del Reglamento de insolvencia (RI) lo hace P. De Miguel Asensio, "Límites de la competencia judicial internacional en material concursal". Disponible: http://pedrodemiguelasensio.blogspot.com/2017/11/ limites-de-la-competencia-judicial.html (última consulta 27/05/2020.

36 TSJUE 12 de febrero de 2009, Asunto 133/78, Gourdain, EU: C- 1979:49, Rec.I-733.

Define resumidamente el criterio Gourdain la STSJUE 19 de abril 2012, ECLI:EU:C:2012:215: una demanda tendrá conexión con un procedimiento de quiebra cuando emane directamente de la quiebra y esté estrechamente relacionada con un procedimiento de liquidación de bienes o de suspensión de pagos, el Tribunal de Justicia precisó que el factor determinante para decidir si se aplica la exclusión de que se trata es la intensidad de la conexión existente

${ }^{37}$ M.A. Penedés Fons, op cit, p 57, siendo una solución que ha venido ganando aceptación mayoritaria por L. CARBALLO PIÑEIRo, "Vis attractiva concursus in the European Union: its.....", op cit. p. 8, con abundante doctrina citada.

${ }_{38}$ En resumidas cuentas, comprobamos que el artículo 6 únicamente se refiere al ámbito competencial de dos tipos de acciones las revocatorias y las conexas-, quedando el resto de las acciones civiles y mercantiles posibles al albor competencial de los criterios plasmados con anterioridad. Aun así, hemos de reflexionar acerca de si lo expuesto es vis attractiva o hemos de complementar el artículo referido con los preceptos siguientes: la dicción del art. 7, referente a la ley aplicable al procedimiento y efectos; el artículo 8 que delimita de forma negativa la afección de la apertura del procedimiento de insolvencia respecto a los derechos reales de un acreedor o de un tercero, así como los artículos 16 ( actos perjudiciales para los intereses de los acreedores),17( protección de los terceros adquirentes) y 18 ( este último referente a los efectos del procedimiento de insolvencia sobre procesos judiciales o arbitrales en curso). Es mi opinión que el conjunto de todos los preceptos acoge una concepción generosa de la vis attractiva concursus en el ámbito europeo. 
45. En aras a agotar razones acerca de la innecesaria labor de interpretación sistemática del Reglamento 2015/848 y de utilización argumentativa de los asuntos Elektrim y Pirelli, sostenemos que se da incluso esa falta de necesidad cuando las normas de competencia de derecho nacional sean aplicables. Pensemos en el supuesto en que el demandado no esté domiciliado en un estado miembro y no resulte aplicable el reglamento sobre procedimientos de insolvencia ni el Reglamento Bruselas I Bis, pues bien, en la búsqueda de la legitimación competencial del juez concursal, se podrá acudir al criterio de la vis attractiva concursus prevista en la ley nacional del juez concursal- tanto en sede judicial como arbitral- revestido de la garantía de que esa forma de proceder no entrara en colisión con las normas del Reglamento de insolvencia, en tanto recogen, como acabamos de ver una vis attractiva amplia, referentes a aspectos concursales y arbitrales ${ }^{39}$.

46. La importancia de lo manifestado es patente. Aunque en el Reglamento de procedimientos de insolvencia 2015/848 no hayamos encontrado una solución del todo óptima y satisfactoria, bien es cierto que ha conseguido un cierto orden dentro de la fragmentación e incertidumbre normativas hasta la fecha inexistentes y que obligaban a esa interpretación sistemática de la que actualmente podemos prescindir.

\section{La aplicación de la ley concursal española sobre el convenio arbitral internacional}

47. En el presente estado de la cuestión, analizados los presupuestos que resultan necesarios para avanzar en el plan establecido, y localizada la norma de conflicto que nos lleva ante el juez que ha acordado la apertura del concurso, nos vemos obligados a adentrarnos en el estudio de la normativa de ámbito nacional. Rescatamos de nuevo los argumentos vertidos por el juez mercantil en el asunto DelFuego Booking y David Guetta, quien se adentra en el régimen jurídico nacional con la finalidad de dar respuesta específica a las cuestiones competenciales y procedimentales que se producen cuando confluyen el concurso y el arbitraje internacional, y lo hace incluso antes de sentar que el Reglamento UE sobre procedimientos de insolvencia resulta ser la norma de conflicto que deriva la cuestión a la lex fori concursus, ex art. 7.2.e), y con la clara finalidad de analizar la eficacia del convenio arbitral, asumiendo la naturaleza contractual, una vez ha sido declarado el concurso de acreedores.

48. Adelantamos ya que en ese análisis judicial de la "eficacia" del convenio arbitral encontramos u error de origen que va a ser tratado en los siguientes apartados. Merece la pena detenerse en el pues la suspensión de los efectos de la cláusula poco o nada tiene que ver con la eficacia o validez, y si con la petición de una medida cautelar El convenio puede ser válido y eficaz pero susceptible de ser suspendido en sus efectos.

49. Es el momento de adentrarnos en el análisis del art. 52. 1 de la $\mathrm{LC}^{40}$, y lo hacemos únicamente del apartado primero, por ser más ajustado a la problemática que en este trabajo quiere abarcarse que no es otra que la controversia planteada en el asunto objeto de análisis, es decir, la suerte que ha de correr la cláusula arbitral de carácter internacional cuando la misma no se ha activado a la fecha de declararse judicialmente el concurso de acreedores, y por ende, abordaremos la respuesta que proporciona el derecho español a asuntos análogos en los concursos internacionales subsumibles en el ámbito del Reglamento UE sobre procedimientos de insolvencia ${ }^{41}$.

\footnotetext{
${ }^{39}$ M. Virgós Soriano y F. Garcimartín Alférez, The European Insolvency Regulation: Law and Practice, Kluwer Law International, La Haya, 2004, p. 63.

${ }^{40}$ Simultáneamente valoraremos el art. 140 del TRLC.

${ }^{41}$ De no ser así, es decir si nos encontramos ante concursos internacionales excluidos del Reglamento, aunque estén abiertos dentro de territorio de la Unión, y a los procedimientos de insolvencia extranjeros y que sean reconocidos en España, para estos supuestos contamos con un régimen propio de Derecho internacional privado que contiene una normativa similar a las soluciones que ofrece el Reglamento de insolvencia, contenido en el Título IX de la LC (199 a 230), o en el libro III, artículos 721 a 752 del Texto Refundido de la Ley Concursal.
} 
50. En la referida sentencia, asunto DelFuego Booking y David Guetta, se sopesa la intencionalidad del legislador en la reforma de la ley Concursal por Ley 11/2011, de 2011, de 20 de mayo, de Arbitraje, que no es otra que la de adaptarse a las soluciones comunitarias en la materia y eliminar la incoherencia existente hasta la fecha, pasando de una regulación contraria a la vigencia de los convenios arbitrales antes de la declaración del concurso a una posición pro convenio arbitral ${ }^{42}$. Por ello la crítica más contundente que hacemos sobre la sentencia es la referente a que tanto la parte concursada como el juzgador no tenga reparos en analizar sin ambages su validez adoptando el término suspensión sin apreciar la incongruencia de tal decisión.

51. Trae el juez a colación la sentencia el asunto Pirelli mostrando su disconformidad con el pronunciamiento que hace respecto a que, con la redacción anterior a la ley 11/2011 del art. 52.1 LC, esta norma era aplicable únicamente a los arbitrajes internos pero no a los internacionales, toda vez que de la dicción legal se deduce solo sería aplicable al caso en la medida en que los citados Convenios internacionales suscritos por España designasen la ley española como ley aplicable para determinar la eficacia del convenio arbitral ${ }^{43}$.

52. En definitiva, considera el juzgador que no se puede expropiar la posibilidad de suspender el convenio arbitral por la declaración de concurso tal y como permite el artículo referido toda vez que la norma de conflicto es el Reglamento de insolvencia, que conduce a la aplicación de la LC para regular los efectos del concurso por lo que los tratados internacionales, (Convención de Nueva York y de Ginebra), que no regulan este aspecto, no pueden poner coto a la referida facultad.

53. No comparto en su integridad las referidas conclusiones y para justificarlas es necesario analizar dos aspectos, uno de naturaleza competencial y otro procedimental que obligan a reparar de nuevo en la concepción que nuestro ordenamiento tiene sobre la vis attractiva concursus además de comprobar si la norma provoca un tratamiento diferente del arbitraje interno y del internacional; adelantando que la aplicación de los Convenios de Ginebra y de Nueva York no tienen por qué ser desterrados definitivamente, una vez se ha localizado la norma de conflicto y esta derive a la ley concursal española como ley que resulta aplicable.

54. Ambas cuestiones son cruciales en este trabajo, dos son las razones de peso: mantengo la consideración de que el juez concursal, al que el Reglamento de Insolvencia le ha atribuido legitimación para enjuiciar la cuestión planteada en el ámbito nacional, que no es otra que la suspensión de los efectos del convenio arbitral al amparo del art 52.1 LC, ha de limitarse a valorar lo que consideramos que es una medida cautelar, por lo que debemos acudir en busca de la competencia del juez concursal para adoptar esa medida cautelar, búsqueda que requiere de nuevo acudir al criterio de la vis attractiva concursus y a la propia ley concursal.

En segundo lugar, sostengo que, con independencia de la valoración que haga de la suspensión de los efectos, el juez puede analizar, bien de oficio o a instancia de parte, la validez de la cláusula compromisoria, si hay méritos para ello, pero no al albor de una mostrada confusión con la posibilidad legal de suspensión que permite el art. 52.1LC, sino al auspicio de la referencia que hace el art. 52.1, in fine, LC: ..todo ello sin perjuicio de los dispuesto en los tratados internacionales., por lo que nos obliga a analizar la segunda de las cuestiones planteadas, es decir, si nuestro ordenamiento se decanta por un sistema monista o dualista.

\footnotetext{
${ }^{42}$ La dicción legal refería "los convenios arbitrales en que sea parte el deudor quedarán sin valor ni efecto durante la tramitación del concurso, sin perjuicio de lo dispuesto en los tratados internacionales".

${ }^{43}$ Según el Tribunal, la Audiencia Provincial de Barcelona en apelación dicta sentencia en 29 de abril de 2009, y en ella, entre otros pronunciamientos salva su aplicación a los arbitrajes internacionales- definidos en su artículo 3- por medio de esa alusión a los tratados internacionales. Fundamenta este criterio la Audiencia señalando como aplicables al caso los Convenios de Nueva York y Ginebra y argumentando a su vez, que el art. 52.1 LC solo sería aplicable al caso en el supuesto de que estos dos Convenios señalasen como ley aplicable la española.
} 


\section{De nuevo con la vis attractiva concursus}

55. Establece el artículo 11 de la $\mathrm{LC}^{44}$ que en el ámbito internacional la jurisdicción del juez del concurso comprende únicamente el conocimiento de aquellas acciones que tengan su fundamento jurídico en la legislación concursal y guarden una relación inmediata con el concurso. El precepto es respetuoso con la concepción europea y con el criterio Gourdain ${ }^{45}$, y en lo que nos interesa, viene a proclamar que la declaración de concurso no es motivo para invalidar una cláusula compromisoria de sometimiento arbitraje.

56. Por su parte, el artículo $8 \mathrm{LC}^{46}$, está especialmente interrelacionado con el artículo 11 del mismo texto legal, en cuanto que este último asume mayores competencias a favor del juez del concurso, no solo de las acciones que tengan transcendencia patrimonial en el concurso sino de todas las ejecuciones independientemente del órgano que las haya acordado, ya sean ejecuciones judiciales o extrajudiciales. El apartado cuarto del artículo 8, alude especialmente a las medidas cautelares adoptadas por los árbitros en las actuaciones arbitrales, sin perjuicio de la competencia del juez para acordar la suspensión de las medidas, o solicitar su levantamiento, cuando considere que puedan suponer un perjuicio para la tramitación del concurso.

57. Pues bien, esa es la premisa que se sigue cuando de arbitraje se trata y así se despacha explícitamente el art. $52 \mathrm{LC}^{47}$ en sus dos apartados, por lo que a todas luces el juez concursal es competente para adoptar la medida cautelar de suspensión de los efectos de la cláusula compromisoria.

\section{Tratamiento del arbitraje: sistema monista o dualista.}

58. En el asunto de referencia el juzgador muestra su disconformidad con lo manifestado en el asunto Pirelli y apoya la postura doctrinal que defiende que han de recibir el mismo tratamiento los arbitrajes internos e internacionales con base en que los referidos convenios a los que alude el art 52.1 $\mathrm{LC}^{48}$, el Convenio de Nueva York y Convenio de Ginebra, no pueden identificarse como la norma de conflicto y selección de ley aplicable, y por ende, es la Ley Concursal la que ha de regular sus efectos.

59. No resultando un hecho discutible, ni de mayor recorrido, lo anteriormente manifestado por el juez concursal, no debemos ser conformistas, debemos ir más allá, en aras indagar si la ley concursal otorga un tratamiento uniforme a todos los arbitrajes a tenor de la dimensión transfronteriza. El tema adquiere importancia desde un punto de vista conflictual; pongamos un ejemplo o ideemos una posibilidad: imaginemos que un tribunal arbitral o judicial ajeno al foro concursal ha de decidir acerca de ese aspecto ya que, según la ley de conflicto, la ley aplicable es la ley concursal española. Es por esta razón por la que el legislador español debiera definirse y optar por un sistema monista o dualista. Pues bien, la Ley Concursal no hace diferenciación expresa entre ambos tipos de arbitraje, salvo en lo referente a la excepción in fine prevista en el art. 52.1 LC, cuando se limita a aludir a los tratados internacionales.

\footnotetext{
${ }^{44}$ Artículo 56 del TRLC, la expresión en ambos preceptos del término "únicamente" nos obliga a pensar en una concepción de la vis attractiva concursus atenuada pero global, al ser respetuosa con el reglamento de insolvencia. El art. 11 entrará a jugar en aquellos casos en que el procedimiento concursal no quede bajo el auspicio del Reglamento de Insolvencia.

${ }^{45} \mathrm{Vid}$. nota a pié de página 36.

${ }^{46} \mathrm{Vid}$. E. Torralba Mendiolea, "Las insolvencias transfronterizas,,,", op cit. p.366. Pese a que reconoce que el art. 8 LC acoge un principio de vis attractiva amplio, el RPI Bis es más limitado lo que no obsta para entender que las acciones vinculadas al procedimiento de insolvencia, sustantiva y procesalmente, son competencia de las autoridades normalmente judiciales, del Estado miembro de apertura del concurso y no de otras que pudieran tener atribuida competencia en virtud de normas comunes de competencia judicial internacional.

${ }^{47}$ Artículo 140 TRLC, aunque el precepto ahora contiene tres apartados.

${ }^{48} \mathrm{Al}$ menos así parece deducirse del ordinal 26 y 27 cuando comienza este último que: cabe discrepar del indicado razonamiento.
} 
60. Parte de la doctrina ${ }^{49}$ considera que la conjunción del art. 52.1 in fine LC y el art. 11 del mismo texto legal es la vía para defender la diferenciación y por ende, la existencia de dos tratamientos distintos del arbitraje nacional y transnacional, aunque catalogan al primero de los preceptos de impreciso por finalizar su dicción con una mera referencia a los tratados internacionales, como si de una excepción a la excepción se tratara. Por mi parte, añadiría a la conjunción doctrinal, en defensa de esa diferenciación, la existencia de un tercer precepto, el $8.4 \mathrm{LC}$ (por la referencia que expresamente hace este artículo a las medidas cautelares y la que este a su vez hace del artículo 52 de la LC en cuanto a las medidas que puedan adoptar los árbitros).

61. Sin embargo, no muestro conformidad con la mayoría de la doctrina que viene valorando la referencia a los tratados internacionales como una redundancia imprecisa y superflua que deriva de la supremacía que reconoce la propia Constitución española a los tratados internacionales de forma que entrarán a formar parte del ordenamiento; como tampoco lo estoy cuando sugieren que los Tratados de aplicación en materia arbitral, como son la convención de Nueva York sobre reconocimiento y ejecución de sentencias de fecha 10 de junio de 1958 y el Convenio Europeo de Ginebra de 21 de abril de 1961 sobre arbitraje comercial Internacional, no resultan de aplicación a la cuestión que nos ocupa, pues considero que pueden resultar aplicables atendiendo a la cuestión que haya de ser enjuiciada ${ }^{50}$.

62. Hay un dato indiscutible, el artículo 52 LC habrá de aplicarse cuando las normas de conflicto remitan al derecho español, pero superado este escollo conflictual, y ya dentro de la legislación nacional previsto por la ley declarada aplicable, puede suceder que debamos acudir de nuevo a los tratados internacionales que anteriormente habíamos desechado. Imaginemos que el juez mercantil supervisa de oficio la posibilidad de suspender la cláusula compromisoria por considerarla perjudicial para la tramitación del concurso y comprueba que la referida estipulación puede estar viciada de nulidad, acudiremos pues a los instrumentos internacionales que anteriormente habíamos desechado por ser, ahora sí de aplicación, dado que la materia objeto de análisis es regulada por los referidos instrumentos.

63. Como corolario de lo expuesto, y como prueba, al menos indiciaria, de que el art. $52.1 \mathrm{LC}$ acoge la diferenciación entre el arbitraje el interno y el internacional lo constata la expresión final al acudir a la alusión de los tratados internacionales, para ello hemos de reparar nuevamente en su redacción: Cuando el órgano jurisdiccional entendiera que dichos pactos o convenios pudieran suponer un perjuicio para la tramitación del concurso podrá acordar la suspensión de sus efectos, todo ello sin perjuicio de lo dispuesto en los tratados internacionales. Por si fuera poco, el Texto Refundido de la LC, no solo no cambia un ápice el sentido de la referencia a los tratados internacionales, sino que le dedica un apartado en exclusiva, el apartado 3 del art.140 que se despacha con la expresión siguiente: "Queda a salvo los establecido en los tratados internacionales".

64. Concluimos con una idea, la intencionalidad del legislador es evidente: si el juez concursal valora la posibilidad de suspensión de los efectos del convenio aplicará la norma nacional, ley aplicable según el Reglamento de insolvencia; pero si lo que valora es la nulidad del convenio, ha de hacerlo trayendo a colación los tratados internaciones de aplicación y que habían sido desechados como norma de conflicto.

\footnotetext{
${ }^{49}$ F. Cordón Moreno, "Concurso y convenios arbitrales (a propósito de la pretendida reforma del art. 52.1 LC)" 23 Anuario de Derecho Concursal, 2011, n 23, pp. 173 y ss. También J. C. Fernández RozAs, Tratado del arbitraje comercial en América Latina, Iustel, Madrid, 2008, pp. 929-930. Vid., para profundizar en argumentos a J. F. GARnica MarTín, "La vis attractiva del juez del concurso tras la reforma introducida por la Ley 38/2011", Anuario de Derecho Concursal, n 26, 2012, pp, 205 y 206.

${ }^{50}$ La doctrina es unánime en este punto, M.F.Martín Moral, "Impugnación de convenios y procedimientos arbitrales fraudulentos", 2013, Revista de Derecho Concursal y Paraconcursal 291, p. 296

No obstante, hay otros autores que se decantan por dar un significado a la expresión, vid. G. Pérez del BlANCO, Efectos procesales de la declaración del concurso: La vis attractiva concursal (Madrid:Reus, 2007) 236-240. En este sentido se pronuncia el Auto de la AP Barcelona (Sección 15ª de 29 abril 2009, pero por razones ajenas a las que yo expongo.
} 


\section{3. ¿Puede entonces el juez concursal acordar la nulidad de la cláusula compromisoria con motivo del análisis de la suspensión de los efectos?}

65. Hemos concluido el ordinal anterior dando una respuesta afirmativa a la pregunta ahora formulada, pero hemos de diferenciar las posibilidades competenciales de las que dispone el juez, es decir, dispone de competencia para acordar la suspensión de los efectos de la cláusula compromisoria $\mathrm{y}$, alternativamente, puede acordar la invalidez de un convenio a tenor de la aplicación de las normas de producción internacional y en vía incidental ${ }^{51}$. Lo que no es admisible es que se confundan ambas posibilidades y se mezclen efectos de forma indiscriminada.

66. Volvamos a traer a colación el Convenio de Nueva York. Reiteremos una vez más que dicho instrumento no se pronuncia respecto a la colisión entre el concurso o insolvencia y los procedimientos arbitrales, pero sí respecto a otras cuestiones, especialmente: el reconocimiento y ejecución de los laudos arbitrales extranjeros, el reconocimiento de la validez formal del convenio arbitral y, por último, el régimen de la declinatoria en caso de convenio. Hemos de recordar que la determinación de la ley aplicable a dicha cláusula compromisoria se realiza de modo separado y distinto a la ley aplicable al contrato principal en el que se inserta o al que se refiere, tiene autonomía Jurídica (art. VI.2 c del Convenio de Ginebra y art. 9.6 Ley de Arbitraje).

67. El Convenio de Nueva York no contempla la posibilidad de que las partes puedan acudir a un tribunal estatal para solicitar, en vía principal, la declaración de inexistencia o nulidad del convenio arbitral. Tampoco está prevista esta posibilidad en el Convenio de Ginebra ni en la Ley 60/2003, de 23 de diciembre de Arbitraje, pues todos ellos parten de una idea básica, la de que tal posibilidad es competencia exclusiva de los mismos árbitros. No obstante, en vía incidental no veo obstáculo para que los tribunales estatales puedan analizar la existencia y validez del convenio siempre que dispongan de un foro de competencia judicial internacional (art. II.3, in fine, Convenio de Nueva York) ${ }^{52}$.

68. Fijados los anteriores asentamientos, ha de traerse a colación, y es de recibo ejemplificar las posibilidades que nos oferta el asunto DelFuego Booking y David Guetta, pues el juez concursal efectúa unas apreciaciones importantes acerca de la cláusula compromisoria, y que apuntan a una falta de bondad, y lo hace con motivo del análisis del grave perjuicio que su activación conllevaría para la tramitación del concurso.

Vaya por delante que no vamos a enjuiciar la validez o nulidad de la cláusula compromisoria, entre otras razones porque no es un acometido anunciado ni se dispone de los datos fácticos necesarios para asumir tan loable función, ni siquiera la del control de incorporación a tenor de la normativa europea, pero lo que si haremos será aprovechar la ocasión para idear las distintas posibilidades con las que contaba el juzgador concursal para poder declarar la nulidad de la cláusula y por ende, con tal decisión dejar abierta la vía jurisdiccional para el ejercicio de la acción de responsabilidad contractual para la que estaría legitimado tanto la concursada como el administrador concursal ${ }^{53}$.

\footnotetext{
${ }^{51}$ La discusión doctrinal y jurisprudencial existe incluso cuando resultan de aplicación normas de producción interna, con motivo de la intervención judicial en el nombramiento de árbitros, Así lo confirma F. Mantilla-Serrano, Ley de Arbitraje. Una perspectiva internacional, Iustel, Madrid, 2005; p. 107. al señalar que "no puede negarse a prestar la asistencia necesaria para permitir la designación del árbitro y la prosecución del arbitraje, excepto cuando le aparezca manifiesta la inexistencia prima facie de convenio arbitral. El juez no podrá examinar ni la validez del convenio arbitral ni la arbitrabilidad de la controversia.

52 Para profundizar sobre este aspecto vid. M. DE BENITO-LLOPIS LLOMBART, "El convenio arbitral: su eficacia obligatoria”, Cívitas Cizur Menor, 2010, pp. 203 y ss y a M. GÓMEZ JENE, "El Convenio Arbitral: statu quo", Cuadernos de Derecho Transnacional (Octubre 2017), Vol. 9, No 2, pp. 7-38, en este último se hace un análisis exhaustivo de la de la jurisprudencia actual (internacional comparada y Española) en interpretación de las normas internacionales y de fuente interna que regulan la eficacia del convenio arbitral.

${ }^{53}$ El juez concursal trata la absoluta incertidumbre de la cláusula compromisoria: no se indica árbitro ni colegio o administrador ni reglamentación bajo la que el arbitraje se desarrollaría....
} 
69. Hemos de hacer una pregunta al juzgador: ¿por qué acordar la suspensión de los efectos una cláusula compromisoria, si la misma es susceptible de anulación? El artículo II.3 del Convenio de Nueva York no pone coto a esta posibilidad pues establece: "El tribunal de uno de los estados contratantes al que se somete a un litigio respecto del cual las partes hayan concluido un acuerdo en el sentido del presente artículo, remitirá a las partes al arbitraje, a instancia de una ellas, a menos que compruebe que dicho acuerdo es nulo, ineficaz o inaplicable”. En armonía con esa dicción, el art. 9.6 de la Ley 60/2003 de 23 de diciembre de Arbitraje proclama que cuando el arbitraje fuere internacional, el convenio arbitral será válido y la controversia será susceptible de arbitraje si cumplen los requisitos establecidos por las normas jurídicas elegidas por las partes para regir el convenio arbitral, o por las normas jurídicas aplicables al fondo de la controversia, o por el derecho español ${ }^{54}$.

70. A tenor de lo anteriormente expuesto ideamos una nueva posibilidad, por ejemplo, la susceptible declaración de invalidez del convenio arbitral por el juez concursal bien porque percibe la concurrencia de vicios del consentimiento o bien la falta de objeto ${ }^{55}$.

71. Que el juez pueda valorar la invalidez de la cláusula en vía incidental, no conllevaría, tal y como hemos adelantado, una derogación del principio Kompetenz-Kompetenz ${ }^{56}$. El análisis ha de efectuarse desde una perspectiva objetiva, así lo prescriben el art. V.1.a) CNY, el art. VI.2.a) CG y los arts. 34.2.a.i) y 36.1.a.i) Ley Modelo de Arbitraje. Esta libertad encuentra su fundamento en el principio de separabilidad del convenio con respecto al contrato principal y constituye un pilar básico del derecho arbitral contemporáneo ${ }^{57}$.

${ }^{54}$ En este sentido se pronuncia el artículo 8.1 de la Ley Modelo UNCITRAL.

${ }^{55}$ Algunos autores consideran que no procede valorarlo: D. GARCía BARTOLOMÉ, "La reciente entrada en vigor del Reglamento Europeo de Insolvencia (y II)" disponible en https://www.abogacia.es/actualidad/noticias/la-reciente-entrada-en-vigor-del-reglamento-europeo-de-insolvencia ( ultimo acceso el 25 de mayo de 2020)/ se trataría de descifrar si la Lex fori concursus podría invalidar o declarar ineficaz dicha cláusula arbitral (latente) para intentar acumular dicho procedimiento ante el juez del concurso, al estilo de la norma contenida en el artículo 51.1 II de la Ley Concursal española, y, la conclusión a la que se llegó en este caso, es que, no existe argumento alguno que permita afirmar que la cláusula arbitral sea inoponible al procedimiento de insolvencia (...)

según los argumentos de F.J GARCÍMARTÍN ALFÉREZ, "El nuevo Reglamento europeo sobre el procedimientos de insolvencia", Revista de Derecho Concursal, núm. 26,2017, pp. 17 y 34: si se aceptase que la lex fori concursus pudiera suspender, invalidar o declarar la invalidez de la cláusula arbitral, el juez que declarara esa invalidez no sería el juez del concurso, pues las cuestiones que se ventilan en los procedimientos de arbitraje (declaración de ineficacia invalidez, de la cláusula arbitral) no son competencia del juez del concurso (art. 6 RPI) y, por tanto, sería competente el juez predeterminado según las reglas generales de competencia judicial internacional (Reglamento Bruselas I). Si se adoptase esta solución se litigaría en un tribunal jurisdiccional competente distinto al juez del concurso (en aplicación del Reglamento Bruselas I), algo no deseado por las partes que pactaron la cláusula por la que decidieron someterse al arbitraje; esa solución tampoco casaría bien con la idea de que el convenio o la cláusula arbitral fuera $a b$ initio inoponible frente al procedimiento de insolvencia, puesto que los que en puridad se pretende con la idea de sostener la inoponibilidad del convenio arbitral — latente - es que se acumule a la vis attractiva del juez del concurso, cuestión nada viable desde el punto de vista procesal, ya que el juez del concurso no es competente para conocer de la declaración judicial de ineficacia o invalidez de la cláusula arbitral, al no ser estas acciones que se deriven directamente del procedimiento de insolvencia o guarden estrecha relación (art. 6 RPI).

${ }^{56}$ La doctrina y la jurisprudencia menor y mayor no es unánime, así lo expone M. DE Benito Llopis-LOMBart, “Análisis jurisprudencial: alcance del efecto negativo de la Kompetenz-kompetenz", Revista del Club Español del Arbitraje, No 1,2008. Los tribunales españoles han seguido tradicionalmente el sistema que entiende que el juez tiene potestad para conocer la cuestión de forma plena e inmediata en cuanto se alegue ante él, mediante declinatoria, la existencia de un convenio arbitral. Tal es el sistema del Convenio de Nueva York, así como el de la Ley Modelo de la Uncitral: el juez debe abstenerse de conocer salvo si "comprueba" que el acuerdo es nulo, ineficaz o inaplicable.

M. GómeZ Jene, “Concurso y arbitraje...”, op cit, pp. 100 y 101, establece: si se defiende que la calificación que merece el convenio arbitral es la de ser un contrato procesal, en la medida de que el Reglamento europeo de insolvencia respeta la realidad extraconcursal (lo que a la postre tiene que ver con la vis attractiva concursus) no cabe declarar su nulidad.

Vid. F.J. CoRdón Moreno, "Declinatoria por sumisión de la cuestión litigiosa a arbitraje: el alcance del enjuiciamiento por el juez del convenio arbitral en que se fundamenta", Análisis, julio 2017, examinando críticamente la Sentencia del TS 409/2017, de 27 de junio establece que la misma se decanta por la "tesis débil del principio Kompetez- kompetez, es decir el órgano debe efectuar un enjuiciamiento completo sobre la validez, eficacia y aplicabilidad del convenio.

${ }^{57}$ Cuestión diferente es la relativa a la ley conflictual aplicable: a la capacidad, a la forma y al fondo del convenio arbitral, por lo que nos remitimos a las normas de conflicto acogidas en la convención de Nueva York, Convenio de Ginebra y ley 60/2003, de Arbitraje. 
72. A mayor abundamiento, no compartimos la opinión doctrinal que rebate lo anteriormente expuesto al sostener que la declaración de ineficacia o invalidez de la cláusula arbitral no es competencia del juez del concurso a tenor de la dicción del artículo 6 del Reglamento 2015/848, sobre procedimientos de insolvencia, ${ }^{58}$ y sí del juez predeterminado según las reglas generales de competencia judicial internacional (Reglamento Bruselas I Bis). El contraargumento es sencillo, si hay una cuestión verdaderamente conexa con el concurso de acreedores esa es la declaración de nulidad de la cláusula y si lo es su suspensión, con mayor razón su nulidad. Ahondaremos sobre ello en el epígrafe siguiente, agotando argumentos a favor de la referida posibilidad.

\section{A vueltas con la suspensión del convenio arbitral. Delimitación conceptual}

73. La reforma del art 52.1 LC por ley 11/ 2011, de 20 de mayo, de Arbitraje, tal y como expusimos, implicó un cambio radical del posicionamiento que la norma tenía hacia los convenios arbitrales, pues pasó de declarar su ineficacia a aceptarlos holgadamente. La dicción legal del precepto no deja lugar a dudas: "la declaración de concurso, por si sola, no afecta a los pactos de mediación ni a los convenios arbitrales, con la excepción de que los mismos pudieran suponer un perjuicio para la tramitación del concurso por lo que el juez podrá acordar la suspensión de sus efectos..." 59 . Sobre esta premisa ha de rondar la interpretación terminológica que haremos del significado de la suspensión de los efectos de la cláusula de compromiso al arbitraje.

74. El término suspensión nos invita a pensar en el hecho de una paralización momentánea de los efectos de la cláusula compromisoria, tanto de los efectos positivos como de los negativos ${ }^{60}$, pero también en que la referida cláusula es susceptible de recobrar su plena eficacia tan pronto como el procedimiento concursal concluya por cualquiera de los medios previstos en el art. 176 y 176 bis de la LC, o bien, porque la medida cautelar de la suspensión de los efectos pierda su razón de ser al entender el juez que ha dejado de resultar perjudicial para la tramitación del concurso. Es erróneo el silogismo: la suspensión del efecto negativo de la cláusula compromisoria pactada de no acudir a la vía jurisdiccional para resolver las controversias ha de conllevar que se active la posibilidad de acudir a la misma. Volveremos sobre ello.

\section{La suspensión acordada en el caso DelFuego Booking y David Guetta}

75. En el ordinal Quinto de la sentencia objeto de tratamiento se analiza el potencial perjuicio que la activación de la cláusula arbitral pudiera conllevar "para la tramitación del concurso". Se parte de un asentamiento escueto acerca del término e implicación de la suspensión considerando que la finalidad de la misma pasa por facilitar el ejercicio de las acciones patrimoniales a favor de la masa concursal; por lo que la suspensión del convenio producirá una reactivación de las normas ordinarias de competencia judicial internacional. Incluso augura el juzgador que la parte que insta la suspensión de los efectos de la cláusula, la concursada, acudirá ante los juzgados de Primera Instancia de Santander. Ante este escenario el juez del concurso analiza el perjuicio del procedimiento.

${ }^{58}$ El referido artículo ha venido a acoger el principio de la vis attractiva, la conexidad de las acciones como premisa competencial a favor del juez del concurso.

${ }^{59}$ La redacción del TRLC, en el artículo 140 viene a ratificar el cambio producido por la reforma 11/2011, de 20 de mayo de la Ley de Arbitraje, aunque su dicción nos lleva a pensar en un reforzamiento de la premisa de validez tanto de los convenios arbitrales como de los pactos de mediación.

${ }^{60}$ El efecto positivo es una manifestación del principio pacta sunt servanda de la que deriva una obligación negativa, es decir las partes se obligan a dirimir sus controversias ante los tribunales arbitrales y, cumplir lo estipulado, equivale a no acudir a la vía jurisdiccional., el efecto negativo se manifiesta cuando alguna de las partes lo hace valer ante la jurisdicción( la declinatoria es el tratamiento procesal para hacer valer la función negativa) según D. Arias LozAno, "Artículo 11", en: D. ARIAS Lozano (Coord.), Comentarios a la Ley de arbitraje de 2003, Cizur Menor, 2005, p.102. 
76. Ante tal asentamiento considero que la valoración que hace el juez del perjuicio para el concurso se sustenta en una base errónea si al efecto de la suspensión de los efectos del convenio arbitral se le aplican por analogía los propios de la declaración de la invalidez o nulidad, porque ambas consecuencias difieren sustancialmente. A mayor abundamiento, ni siquiera el juez se plantea en vía incidental analizar la validez del convenio arbitral después de exponer toda una serie de incertidumbres que le sugiere la cláusula compromisoria ${ }^{61}$.

77. No resulta baladí traer a colación nuevamente los pronunciamientos efectuados en la Exposición de Motivos de la Ley 11/2011, de 20 de mayo, en tanto que la reforma del artículo 52.1 LC tenía como finalidad "mantener la vigencia del convenio arbitral siempre que se proyecte sobre meras acciones civiles..."; luego, si la suspensión se equipara a la nulidad de la cláusula y como efecto conlleva la reactivación de las normas de competencia judicial internacional, es evidente que se deja al convenio vacío de contenido y por ende, sin efecto alguno. Prueba de que así lo entiende el juzgador es la valoración que hace del perjuicio para el concurso por la posible activación de la cláusula compromisoria; y también por un dato omitido, el no referir en la resolución dictada cual es el plazo de suspensión al que somete el convenio arbitral.

78. Si la Exposición de Motivos de la referida ley se expresaba claramente en el sentido expuesto, también lo hacía la redacción del precepto 52.1 LC anterior a la reforma acometida en el año 2011, cuando se refería a la suerte que corría el convenio arbitral: "los convenios arbitrales quedarán sin valor ni efecto alguno durante la tramitación del concurso, sin perjuicio de lo dispuesto en los tratados internacionales". En consecuencia, es evidente que la reforma pretendió dar un giro radical en la referida cuestión; si no respetamos el sentido de la misma el resultado obtenido es contra legem.

79. No huelga destacar que con anterioridad a la reforma del año 2011 ya resultó problemático fijar qué tipo de ineficacia era la que procedía, pues parte de la doctrina defendía que el convenio arbitral, válidamente celebrado, seguía siendo válido, aunque posteriormente una de las partes del convenio fuera declarada en concurso. Lo único que sucedía es que se suspendían los efectos del convenio en relación a esa parte, siempre condicionado a que resultara perjudicial para el procedimiento concursal. Por eso, en caso de que el convenio afectara a una relación jurídica con pluralidad de sujetos, el hecho de que uno de ellos se declarara en concurso no impediría a los restantes poder dirimir sus conflictos mediante el arbitraje. Prueba de ello es que el convenio arbitral sigue siendo válido, aunque sus efectos se suspenden respecto a la persona declarada en concurso $^{62}$.

${ }^{61}$ Por Auto del Juzgado mercantil número 10 de Barcelona, 26 de octubre de 2012, http://www.mobiliariamonesa. com/09/2.1.\%20AUTO\%20SUSPENSION\%20CLAUSULA\%20ARBITRAL.pdf,se acuerda por el juez concursal la suspensión de los efectos de cláusula compromisoria al albor del art. 52.1 LC, pp. 9 y ss, pero lo hace como una medida definitiva alejada de cualquier alzamiento de la suspensión, aunque alega que la no suspensión de los efectos conllevaría que el concurso no finalizaría hasta que se resuelva todas las cuestiones en el procedimiento arbitral al ser litigioso o contingente el crédito

${ }^{62}$ Entre otros, por Manuel Jesús Marín López. Este comentario ha sido realizado dentro del Proyecto BJU2002-00590 de la Dirección General de Enseñanza Superior e Investigación Científica, del Ministerio de Ciencia y Tecnología ("Las garantías del crédito en las situaciones concursales (en especial, las garantías financieras relativas a los valores anotados en cuenta)", que dirige el Prof. Ángel Carrasco Perera.

Disponible en: https://previa.uclm.es/profesorado/mjmarin/invest_cap_4_art52.pdf .(no consta más referencia de la obra ni del autor que la citada). El autor refiere:

El convenio arbitral no va a producir efectos. Como se sabe, el convenio arbitral tiene una doble eficacia, positiva y negativa. Tiene una eficacia positiva, en el sentido de que "obliga a las partes a cumplir lo estipulado" (art. 11.1 LArb), es decir, a someter a arbitraje las controversias que hayan surgido o puedan surgir respecto de una determinada relación jurídica (art. 9.1 LArb). La eficacia negativa consiste en que el convenio arbitral impide a los tribunales conocer de las controversias sometidas a arbitraje, siempre que la parte a quien interese lo invoque mediante declinatoria (art. 11.1 LArb). En consecuencia, la suspensión de los efectos del convenio arbitral significa: a) por una parte, que las partes del convenio ya no están obligadas a someter las controversias jurídicas que entre ellas surjan o puedan surgir a arbitraje; $y$ b) por otra, que cualquier de las partes tiene vía libre para acudir a los tribunales y ejercitar en ellos las acciones judiciales que estime pertinentes. Y ello es así con independencia de que la parte que celebró el convenio arbitral, y después es declarada en concurso, ocupe en ese nuevo proceso judicial que se va a iniciar la posición de demandada (art. 50 LC) o de demandante (art. 54 LC). 
80. Es evidente qué a tenor de la redacción actual esas dudas han quedado disipadas pues se ha cambiado rotundamente el criterio al establecer que la declaración de concurso puede provocar la suspensión de los efectos del convenio arbitral, efectos que no desaparecen de forma definitiva, sino de manera provisional y durante la tramitación del concurso. Por lo tanto, cuando la tramitación del concurso concluya, la suspensión de los efectos decae, y el convenio arbitral recupera la doble eficacia positiva y negativa ${ }^{63}$.

\section{La suspensión de los efectos del convenio: una medida cautelar}

81. Lo anteriormente expuesto nos permite pensar, tal y como expusimos en el epígrafe IV de este trabajo, en que la suspensión acordada comparte los fundamentos que sustentan la adopción de una medida cautelar. Y por si cupiera alguna duda acerca de la falta de competencia, el artículo 8.4 de la LC incluye como una materia exclusiva y excluyente de la competencia del juez concursal, la referente a la suspensión de las medidas cautelares adoptadas por los árbitros, o la de solicitar su levantamiento, cuando considere que pueden suponer un perjuicio para la tramitación del concurso. Y si la duda surgiera por lo que respecta a la internacionalización del arbitraje, refiere el precepto que se hará de acuerdo con lo dispuesto en el art. 52 LC, y sin diferenciar el contenido de sus dos apartados, es decir ya se haya iniciado, o no, el procedimiento concursal ${ }^{64}$. Como corolario de lo expuesto, no cabe pues margen de duda acerca de la legitimación del juez concursal para adoptar una medida provisional de suspensión de los efectos del convenio como la que nos ocupa.

\section{El perjuicio para la tramitación del concurso como causa de la suspensión}

82. El artículo 52.1 LC supedita la suspensión del convenio arbitral al potencial perjuicio que pudieran suponer la activación y/ o eficacia de los pactos de mediación y convenios arbitrales para la tramitación del concurso. Aun así, valorada la posibilidad, permite al juez concursal que pueda o no acordar la suspensión de los efectos.

\section{La valoración judicial del perjuicio en el asunto DelFuego Booking y David Guetta.}

83. Pese a la escasez de estudios valorando el perjuicio concursal, entiendo que la interpretación que se haga del término "suspensión" condicionará necesariamente la que se haga de la valoración del "perjuicio para la tramitación del concurso", pudiendo llegar a conclusiones diametralmente opuestas según se adopte una u otra.

84. En la sentencia de referencia aprecio que se produce un segundo error de base. Es cierto que en la referida resolución se valoran los distintos posicionamientos doctrinales que hay al respecto; los que entienden que únicamente cabría la suspensión del convenio si pudieran provocar "obstáculos de naturaleza procesal" para la tramitación del concurso, ya que la ley habla de "perjuicios para la tramitación "y no de "perjuicios para el concurso". De seguirse esta corriente doctrinal, refiere el juzgador, no

\footnotetext{
${ }^{63}$ Incluso hay quien llega más allá, M. GómEz JENE, "El convenio arbitral....", op cit, p. 34, se plantea como especialmente controvertido determinar si el convenio arbitral deviene ineficaz - o sin valor-cuando las partes implicadas - o una de ellas- sean economicamente insolventes, entendiendo que únicamente la voluntad de la pare solvente de asumir los costes del arbitraje puede salvar dicha eficacia. Sin embargo, si la solvent no está en disposición de cubrir también los honorarios de los letrados de la contraparte (..) se ha estimado que el convenio arbitral debe perder su eficacia. Refiere en nota a pie de página que en la jurisprudencia española ha de verse el AP de Barcelona de 29 de abril de 2009, EDJ 2009/260256.

${ }^{64}$ M. Virgós Soriano Y F. Garcimartín Alférez, The European..., op cit., 63, excluyen la tutela cautelar del ámbito exclusivo del juez concursal.
} 
podríamos ampararnos en los costes del arbitraje o las consecuencias económicas para el concurso de acreedores. El juzgador, avalado por precedentes judiciales, entiende que el procedimiento, como mero trámite, no es digno de protección ni puede sufrir un "perjuicio". Otro sector de la doctrina, como continúa refiriendo el juez concursal, ${ }^{65}$ apunta (además de los supuestos de maquinaciones fraudulentas) al "interés del concurso" que permite resolver contratos no afectados por la declaración de insolvencia (art. $61 \mathrm{LC})$. Así, el posible perjuicio habrá de definirse a la luz del interés colectivo de todos los acreedores concurrentes, o en su caso, a conservar o incrementar la integridad y el valor de los activos del deudor en beneficio de los acreedores.

85. En atención a lo expuesto, en la sentencia se plasma la valoración del perjuicio haciendo una comparativa de costes entre el procedimiento arbitral y el judicial, partiendo de una premisa que anuncia en el punto 35 de la sentencia, la referente a que la suspensión del convenio producirá una reactivación de las normas ordinarias de competencia judicial internacional ${ }^{66}$. Reiteramos el desacuerdo con la anterior conclusión, toda vez que la suspensión debe conllevar únicamente la paralización temporal de la facultad de las partes suscritoras del compromiso para acudir a la vía arbitral. La conclusión a la que llega el juzgador únicamente procedería si se acuerda la nulidad del convenio.

86. No podemos estar más en desacuerdo con la valoración que hace del mismo el juez concursal partiendo de la referida comparativa de costes; es el juez quien reconoce la vaguedad de la cláusula compromisoria (susceptible de haber sido cuestionada su validez), así como el hecho de que la masa activa del concurso no dispone de tesorería siendo su principal activo el crédito que se arroga frente al artista indicado. Concluye refiriendo que: el perjuicio es evidente desde el momento en que, la posibilidad de que los miles de consumidores de la concursada pudiera llegar a algún tipo de recuperación de sus créditos en el concurso, pasa por el éxito (por lo tanto por la posibilidad) de la indicada reclamación de la promotora concursada frente al artista presuntamente responsable del incumplimiento contractual, resultando inviable (por su coste), de no suspenderse el convenio arbitral, que perjudica de tal manera a la tramitación del concurso al punto de convertirlo en inútil.

87. Sobre esta última reflexión he de apuntar que lo que verdaderamente puede resultar perjudicial para el procedimiento concursal es acordar la suspensión del convenio arbitral. Reparemos en que, sin apenas activo, es casi seguro que el propio procedimiento concursal, que habrá generado unos gastos nada desdeñables para la masa, finalice sin éxito por insuficiencia de masa activa y a expensas de una posible reapertura del concurso si se consigue una estimación integra de las pretensiones indemnizatorias frente al artista en el procedimiento de reclamación por incumplimiento contractual. No obstante, es significativo no obviar que la reapertura del concurso queda condicionada a que se obtenga resolución firme en un plazo de cinco años (art. 179 LC).

88. Valorar el perjuicio también ha de conllevar el análisis de la viabilidad de la referida reclamación por incumplimiento contractual, máxime cuando ya se toma como algo plausible el potencial éxito de la reclamación del crédito que la concursada se arroga frente al artista, pero también el de las inevitables dilaciones de la administración de justicia ${ }^{67}$ que se producen con motivo de la tramitación de un procedimiento declarativo ordinario, desde su incoación hasta obtener una sentencia firme. Luego,

${ }^{65}$ M. A. PenedÉs Fons, op cit. pp. 143-145. Reconoce el autor, que dado el silencio hermenéutico del art. 52.1 LC, sobre el significado del término perjuicio puede suplirse a través del recurso a expresiones similares empleadas por el legislador en otros puntos, como el art. 61LC, que ofrece un útil criterio para que el juez concursal pueda ordenar la resolución contractual. En este sentido ha de estarse: al interés de la masa e interés del concurso, aunque es materia polémica. No obstante, el autor refiere, (con lo que no muestro conformidad), que la evaluación sobre los posibles perjuicios deberá hacerse de acuerdo con los costes y trámites requeridos por el foro que sería verdaderamente competente en ausencia de pacto arbitral.

${ }^{66}$ En este sentido opina I. Heredia Cervantes, Arbitraje, concurso internacional...Op cit. pp. 5, en comentarios a la referida sentencia, llegando a la misma conclusión que la que se expone en la sentencia.

${ }^{67}$ Valoramos el perjuicio según el criterio de la sentencia que la analiza, por ello valoramos la dilación de la administración de justicia a la vía a la que aboca el juez a la parte concursada que solicita la suspensión. 
consideramos que la suspensión, tal y como la interpretamos, conllevaría un retraso temporal considerable en obtener una resolución favorable respecto a una pretensión que tiene visos de prosperabilidad, por no decir, una causa o razón que permita forzar un acuerdo extrajudicial entre las partes contratantes. En consecuencia, el perjuicio de los acreedores estaría servido si obviamos los razonamientos apuntados y, por ende, se acuerda la suspensión de los efectos de la cláusula compromisoria.

89. Con todo ello, hemos de hacernos la siguiente pregunta: ¿qué sucedería en el asunto objeto de análisis si no se acuerda la suspensión de los efectos del convenio arbitral? ¿implicaría que el procedimiento concursal no finalizará hasta en tanto no se resuelva la cuestión controvertida en el procedimiento arbitral, en caso de haberse activado el convenio arbitral?; la respuesta ha de ser negativa, no impediría la terminación del procedimiento concursal, aunque el posible reintegro de activo a la masa a tenor del laudo arbitral que se dicte pudiera conllevar una reapertura del procedimiento concursal (art. 179. 2 y 3 LC).

90. No es efímera la diferencia entre acordar la nulidad de un convenio arbitral y la mera suspensión cautelar de sus efectos, pues la invalidez de la cláusula compromisoria acordada judicialmente sí permitiría la activación de las normas sobre competencia judicial internacional, que es lo que parece desear el juzgador y, por ende, avanzar en la resolución de la controversia. De no hacerlo así, aventuramos una inútil finalidad del concurso de acreedores que terminará por insuficiencia de activo y sobrecargado de costes y transcurso de tiempo baldío. No obstante, el juez concursal considera el crédito frente al artista prácticamente el único activo del que dispone la empresa concursada. La trascendencia patrimonial que para el deudor concursal tiene la reclamación frente a la parte que ha incumplido el contrato y ha provocado la situación de insolvencia, es ciertamente crucial para valorar la suspensión de los efectos del convenio y su íntima relación con el perjuicio que la suspensión puede o no ocasionar.

91. En consecuencia, el perjuicio no puede venir referido a la existencia misma del convenio arbitral, pues, tras la reforma del artículo 52 LC por ley $11 / 2011$, de 20 de mayo $^{68}$, ha demostrado que el legislador no concibe el arbitraje como una opción menos válida o más perjudicial que la tramitación judicial, sino que parte de su equivalencia a los efectos concursales ${ }^{69}$. Prueba que refuerza lo anteriormente expuesto es que el precepto equipara al convenio arbitral con los pactos de mediación a los efectos suspensivos.

\section{El fraude como causa de anulación de los convenios a tenor de la norma concursal.}

92. Una de los razones que abonan la justificación referente a que la suspensión de los efectos del convenio goza de naturaleza cautelar y no definitiva, se halla en la previsión acogida en el artículo 53.2 $\mathrm{LC}^{70}$ así como en el apartado 4 del artículo 140 del TRLC, en los que se prevé, para el caso de fraude, la legitimación de la administración concursal para impugnar ante el juez del concurso tanto los

${ }^{68}$ En este estado de la cuestión, el TRLC en su artículo 140, actual 52.1 LC, clarifica los extremos de la suspensión, en cuanto a la legitimación y momento procesal en que puede regir, pero sigue utilizando el mismo término sin variar un ápice en su significado, ni siquiera en la discrecionalidad del juez en cuanto a la valoración del perjuicio.

${ }^{69}$ M.A.Penedés Fons, op cit, pp. 143 y 144: Sin lugar a dudas, los escenarios más claros para el ejercicio de la potestad suspensiva del art. 52.1 LC se darán cuando sea posible identificar la existencia de maquinaciones fraudulentas entre el deudor y alguno o algunos de sus acreedores que pretendan emplear el arbitraje como mecanismo evasor de los imperativos concursales.463 Sin perjuicio de la obvia dificultad de probar el fraude a través de la mera conclusión de un convenio arbitral sin que ésta haya dado lugar a procedimiento o laudo alguno,464 la posibilidad de suspender en estos casos el pacto arbitral es coherente con la acción especial que también prevén los 53.2 y 86 LC para impugnar los laudos dictados como consecuencia de prácticas fraudulentas en el seno del arbitraje.

${ }^{70}$ La dicción de este artículo merece ser reproducido: 1. Las sentencias y los laudos firmes dictados antes o después de la declaración de concurso vinculan al juez de éste, el cual dará a las resoluciones el tratamiento concursal que corresponda. 2. Lo dispuesto en este artículo se entiende sin perjuicio de la acción que asiste a la administración concursal para impugnar los convenios y procedimientos arbitrales en caso de fraude. 
pactos de mediación como los convenios y procedimientos arbitrales, es decir dispensa la posibilidad de acordar la nulidad o rescindibilidad de los convenios y procedimientos arbitrales, diferenciándola del apartado que prevé la mera suspensión de los efectos. Pues bien, considero que esta novedad también introduce una nueva delimitación del perjuicio, el interés de la masa ${ }^{71}$.

93. En el asunto Delfuego Booking y David Guetta se alude a las maquinaciones fraudulentas con motivo de la valoración que el juez concursal hace del perjuicio asumiendo los distintos criterios doctrinales que se han pronunciado al respecto y de las soluciones hermenéuticas que se han desarrollado a tenor de la LC..$^{72}$ No refiere el juzgador que la cláusula arbitral del contrato sea fraudulenta, pero si aprovechamos la ocasión para exponerla como una de las posibilidades que el juez tenía a su disposición para declarar la ineficacia de los efectos del convenio arbitral.

94. No obstante, por coherencia sistemática nos vamos a ceñir al análisis del fraude en el convenio arbitral previamente a haberse incoado procedimiento alguno, anticipando de antemano la primera dificultad con la que nos encontramos, la de su acreditación ${ }^{73}$, no sin antes haber salvado otra, la de definir en qué ha de consistir ese fraude, pues ni siquiera la norma especifica si ha de ser un fraude legal o procesal.

95. Partimos nuevamente de las causas de nulidad del convenio arbitral e ideamos la posibilidad de que pueda resultar contrario al orden público -al concurrir fraude de ley en la estipulación-, o bien por no cumplir los requisitos esenciales del contrato, es decir por falta de consentimiento, objeto o causa. $\mathrm{O}$ supongamos que la cláusula arbitral prevista en el ordinal 18 del contrato del asunto DelFuego Booking y David Guetta tuviera por objeto una causa falsa, evadir las normas de competencia judicial obligando a la contraparte a un arbitraje que no se delimita en absoluto pues no respeta ni el contenido necesario ${ }^{74}$, es decir, se pretenda imponer a la contraparte tal cláusula como condición para la contratación por lo que la manifestación ni es libre ni es consciente, vulnerando el derecho a la tutela judicial efectiva, ex art. 24 de la Constitución Española. En conclusión, la finalidad de insertar una cláusula compromisoria puede estar en blindar al arbitraje ante un procedimiento concursal.

96. El fraude puede estar servido, como en su momento lo expusimos con motivo del análisis de la posibilidad de declaración de nulidad de la cláusula compromisoria de oficio por el juez concursal. Hay potenciales razones de peso para que el juez pueda valorar la posible patología del convenio arbi-

${ }^{71}$ No obstante, en el artículo 53 LC ya se aludía al fraude como causa de impugnación por parte del administrador concursal pero respecto convenios y procedimientos arbitrales, sin que la competencia se atribuya al juez concursal.

${ }^{72}$ El juez concursal citando a M. A. PENEdÉs Fons ( $\sin$ reseñar cita), valora las distintas posiciones doctrinales en los puntos de la sentencia: 31 a 34 (este el referido a los supuestos de maquinaciones fraudulentas), para concluir en el punto 35 que la suspensión del convenio produciría una reactivación de las normas ordinarias de competencia judicial internacional, con lo que manifesté, no estaba de acuerdo.

${ }^{\text {Lo }}$ conecta el juez con el "interés del concurso" que permite resolver contratos en principio no afectados por la declaración de insolvencia (art. $61 \mathrm{LC}$ )

${ }^{73}$ STS 6 de octubre de 2015, ECLI: ES:TS:2015:4125.La doctrina de esta Sala ha recordado que la maquinación fraudulenta precisa de prueba cumplida de hechos, que, por sí mismos, evidencien que la sentencia ha sido ganada por medio de ardides o artificios tendentes a impedir la defensa del adversario, de suerte que concurra un nexo causal eficiente entre el proceder malicioso y la resolución judicial ( STS de 9 de diciembre de 1999 y las en ella citadas), y que no se autoriza a los litigantes a proponer un nuevo examen de las cuestiones que ya tuvieron un lugar adecuado en el pleito y la revisión ha de basarse en hechos ajenos al pleito ( STS de 14 de enero de 1988 ).

${ }^{74}$ Dados los términos genéricos expuestos, tales como la causa, el objeto de la controversia, y para profundizar sobre ellos vid al profesor L. Martínez VÁzQuez De CAStro, La cláusula compromisoria en el arbitraje civil, Civitas, Madrid, 1991, p.115 "la causa típica del convenio arbitral es el apartamiento de la jurisdicción ordinaria para someterse a lo que podríamos denominar el Tribunal arbitral. Por otra parte, J, Merino Merchán, y J, Chillón Medina: Tratado de Derecho Arbitral, Ed. Civitas, $14^{\mathrm{a}}$ ed, pp. 216-217, postulan la cuestión objeto de controversia como causa del arbitraje.

Para L. Prats Albentosa, «Art. 9» en Comentarios a la Ley de Arbitraje, La Ley, Madrid, 2013, pp. 243-245, es la libertad de las partes la razón de ser del convenio arbitral, siempre que la materia sea disponible y concurran todos los requisitos que para su validez y eficacia. Lo que nos lleva a pensar que ha de analizarse cada caso para visualizar y comprobar la existencia de vicios en las clausulas compromisorias. 
tral, pues la cláusula no refiere qué controversias son susceptibles de arbitraje - ni siquiera refiere que las mismas sean las que puedan dimanar del contrato- ni ningún otro aspecto del mismo. Reparemos en un dato fundamental, si bien la suspensión de la cláusula puede ser acogida de oficio por el juez, la declaración de su nulidad por fraude ha de ser instada por el administrador concursal, como único legitimado, asumiendo de plano el juez del concurso la competencia para su enjuiciamiento.

97. Pues bien, ya en cuanto a su naturaleza, la acción de impugnación goza de la similitud de las acciones rescisorias concursales a solventar por el incidente concursal, en especial las integradas en el art. 71.1 LC (como actos perjudiciales para la masa) por lo que nos volvemos a topar con un problema competencial que, de nuevo, el reciente texto Refundido de la LC también omite. Sin embargo, consideramos que el problema está saldado pues el juez concursal está amparado por lo dispuesto en el artículo 6.1 del Reglamento de procedimientos de insolvencia 2015/848. El precepto refiere que podrá conocer sobre las acciones que deriven directamente del procedimiento de insolvencia y tenga una estrecha vinculación con éste (el artículo ejemplifica con las acciones revocatorias) el órgano judicial en el que se haya abierto un procedimiento de insolvencia principal ${ }^{75}$. Por si alguna duda cupiere, también está amparado por el art. $7.2 \mathrm{~m}$ ) que establece que será la ley del Estado de apertura la que determinará las condiciones de las normas relativas a la nulidad, anulación o inoponibilidad de los actos perjudiciales para el conjunto de los acreedores ${ }^{76}$.

\section{A modo de cláusula de cierre, y a vueltas con la reverencia que el art. 52.1 in fine LC hace a los tratados internacionales}

98. La consecuencia general prevista en el art. 52.1 LC sobre la suspensión de los efectos encuentra una anotación al final del precepto pues refiere que todo lo acogido en su dicción lo es "sin perjuicio de lo dispuesto en los tratados internacionales". Ya hemos abordado, con motivo del análisis del sistema monista o dualista y del tratamiento y la posibilidad que tiene el juez de acordar en vía incidental la nulidad de la cláusula compromisoria, como la mayoría de la doctrina considera que la referencia a los tratados internacionales es innecesario e inútil, por obvia, en cuanto que es evidente que los tratados internacionales en los que España sea parte se aplicará con preferencia a lo establecido en la LC; además, no existen a la fecha tratados que versen sobre arbitraje e insolvencia y hagan referencia a lo tratado en el art. 52.1 $\mathrm{LC}^{77}$. Ya mostramos la utilidad del precepto y la disconformidad con la doctrina.

\section{Efectos de la resolución judicial acordando la suspensión frente a terceros Estados miembros de la UE}

99. La consideración que de nuevo me lleva a pensar acerca de que la referencia que hace el precepto 52.1 de la LC ni es impertinente ni es inútil, ${ }^{78}$ se nutre de una segunda razón de peso que viene a reafirmar la convicción de su utilidad y que tiene mucho que ver con los efectos extraterritoriales de la resolución judicial que declara la suspensión de la cláusula arbitral: ¿es posible hacer valer la resolución de suspensión de la eficacia del convenio arbitral en el ámbito internacional en aplicación del art.

\footnotetext{
${ }^{75}$ No olvidemos reparar en el actual art. 199 LC y el art. 720 del TRLC. Este último precepto establece que las normas de este libro se aplicaran sin perjuicio de lo establecido en el Reglamento sobre procedimientos de insolvencia de fecha 20 de mayo de 2015.

${ }^{76}$ No obstante, difiere la impugnación por fraude y la acción rescisoria en cuanto al elemento perjuicio, toda vez que en la acción rescisoria no se requiere que concurra fraude sino únicamente perjuicio para la masa activa del concurso.

${ }^{77}$ El Texto Refundido de la Ley Concursal cambia la redacción, pero no el sentido, y en el art 140.3 in fine establece que: "Quedan a salvo los tratados internacionales".

${ }^{78}$ Tratamos el precepto en las pp.21- 23.
} 
52.1 LC?, y en su caso, ¿bajo el auspicio de qué instrumentos internacionales podemos hacer valer la sentencia que acuerda la suspensión de los efectos de la cláusula?

100. Traigamos a colación de nuevo el asunto DelFuego Booking y David Guetta ${ }^{79}$ : supongamos que, habiendo acordado el juez concursal la suspensión de los efectos de la cláusula, el artista decide iniciar el arbitraje ante el tribunal arbitral o ante los órganos jurisdiccionales franceses, por ser este el país donde tiene el domicilio del actor. Sin embargo, bien la administración concursal o la entidad mercantil concursada, o ambos, quieren hacer valer ante esos tribunales la resolución acordando la suspensión de la cláusula o convenio arbitral.

101. No podemos acudir al Reglamento de Bruselas I Bis toda vez que queda excluida de su ámbito la materia referente a arbitraje y a la quiebra. Se nos presenta un segundo problema, el tribunal arbitral puede comenzar por no reconocer la existencia de la situación concursal, y ya hemos analizado que desde la perspectiva del Derecho arbitral no existe una norma de conflicto que disponga qué ley ha de regir los efectos que el concurso produce sobre un procedimiento arbitral internacional, como ocurre en este caso en que la sede arbitral queda fuera del estado de apertura de concurso, pues se localiza en Londres ${ }^{80}$.

102. Es decir, no ha de descartarse la posibilidad de que los árbitros, y por motivos de prudencia, puedan suspender el arbitraje y sugerir a las partes que soliciten la homologación de concurso directamente ante los tribunales de la sede arbitral (en este caso Londres). Aunque ello implique recurrir al ámbito judicial del que las partes pretendían huir; esta decisión permitiría garantizar la utilidad del procedimiento arbitral y evitaría el riesgo de que árbitros y jueces alcanzaran conclusiones incompatibles al respecto ${ }^{81}$.

103. Es una solución óptima sentada en el principio de reciprocidad porque a la postre robustece en vía de regreso el laudo arbitral. No obstante, no olvidemos que también puede tener cabida el orden público como sustento de la denegación del reconocimiento y ejecución del laudo en base a que se hizo caso omiso a una resolución judicial acordando la suspensión.

104. Reforzamos lo anterior trayendo a colación el Reglamento de procedimientos de insolvencia 2015/848, en sus artículos 19 y 32, pues vienen a sentar que las resoluciones relativas al desarrollo y conclusión de un procedimiento de insolvencia por parte del órgano jurisdiccional así como los convenios aprobados por dicho órgano jurisdiccional, se reconocerán asimismo de pleno derecho y se ejecutarán con arreglo a los artículos 39 a 47 y artículos 47 a 57 del Reglamento (UE), n 1215/2012. El artículo 32 extiende lo anteriormente expuesto a las resoluciones dictadas relativas a las medidas cautelares y adoptadas tras la solicitud de apertura de un procedimiento de insolvencia o en relación con esta, pero especifica en el apartado 2, que, en el caso de tratarse de resoluciones diferentes a las referidas en el apartado primero, el reconocimiento y la ejecución se regirán por el reglamento 1215/ 2015 siempre que dicho reglamento sea aplicable.

\footnotetext{
${ }^{79}$ Aunque esta posibilidad no fue abordada por el juez concursal con motivo de la valoración del perjuicio para la tramitación del concurso.

${ }^{80}$ La posibilidad de que el juez concursal pueda recurrir al art. 52.1 LC deriva de la norma de conflicto contenida en el art. 7.2.e) RI, según la cual ha de ser la lex fori concursus la que regule el efecto que la declaración de insolvencia produce sobre los convenios arbitrales concluidos por el deudor. Sin embargo, si la administración concursal decide ejercitar una acción judicial contra B y ésta presenta una declinatoria de jurisdicción solicitando el reconocimiento del convenio, ¿es este régimen directamente aplicable en ese contexto?

${ }^{81}$ M.A. Penedés Fons, Insolvencia transfronteriza ...., p. 298, referenciando el caso inglés Kombinat Aluminjuma Podgorica AD (In Bankruptcy), Re [2015] EWHC 750 (Ch), en el que el tribunal arbitral LCIA con sede en Londres decidió acudir a los jueces ingleses para acudir el levantamiento de la suspensión automática de arbitrajes del deudor que prevé el Derecho concursal inglés para insolvencias extranjeras que hayan sido reconocidas. Igualmente, vide Re Pan Ocean Co. Ltd; subnom Seawolf Tankers Inc and another v Pan Ocean Co Ltd and another [2015] EWHC 1500 (Ch).

En este sentido se pronuncia M. Gómez JENE, “El convenio....”, op cit. p. 37.
} 


\section{Reconocimiento de los efectos de la resolución suspensiva frente a Estados no miembros de la UE. Una problemática añadida en el asunto DelFuego Booking y David Guetta}

105. Es un hecho previsible que las dificultades con las que nos hemos encontrado pueden no tener fin con el dictado judicial que acuerda la suspensión de los efectos de la cláusula compromisoria, sino que pueden sucederse si una de las partes, obviando la resolución judicial, intenta activar la cláusula ante los tribunales arbitrales de la sede pactada, en nuestro caso en Londres.

106. Para hacer valer la resolución que acuerda la suspensión de los efectos del convenio arbitral frente a un tercer estado que no sea Estado miembro de la Unión Europea, acudiremos de nuevo a la normativa acogida en los Convenios de Nueva York y de Ginebra, por ser ambos Estados parte y regular la declinatoria de jurisdicción. Cuestión diferente es que pudiera no resultar efectivo si las normas de conflicto del Convenio de Ginebra (art. VI) no remiten a la legislación española y por ende resultaría probable que no surta efectos la resolución acordando la suspensión ${ }^{82}$.

107. Es una lectura acorde con la filosofía defendida por la propia UNCITRAL, cuya Guía de Incorporación de la Ley Modelo de Insolvencia afirma que las reglas concursales que prevén la invalidez o la ineficacia (indefinida o temporal) del convenio arbitral como consecuencia de procedimiento concursal "no son contrarias al Convenio sobre reconocimiento y ejecución de sentencias arbitrales de 1958".

108. No obstante, hemos de ceñirnos a los efectos de la suspensión, no como ineficacia del convenio, sino como una medida cautelar, posición esta que venimos defendiendo durante el presente trabajo, al considerar que goza de la naturaleza de medida provisional y en tanto no se acuerde la finalización del concurso, momento en el que adquiere todo su fuerza y vigor ${ }^{83}$.

109. Recreémonos finalmente en la siguiente situación hipotética, trayendo a colación el asunto judicial objeto de análisis y en la necesidad de hacer valer ante el tribunal arbitral la sentencia del juzgado de lo mercantil: el tribunal arbitral que hubiese sido designado puede defender que, al no estar Reino Unido en la Unión Europea no resulta de aplicación, ni el Reglamento de procedimientos de insolvencia, ni el Reglamento Bruselas I Bis ${ }^{84}$, por lo que, aun reconociendo la suspensión de la cláusula arbitral por sentencia, consideran que no han de interferir suspensivamente en el procedimiento arbitral que se está válidamente desarrollando en Londres, máxime cuando no ha sido declarada nula la cláusula compromisoria a tenor de los instrumentos internacionales, el Convenio de Nueva York y al de Ginebra, que por ser España un país parte, le obliga a respetar.

110. Son varias las preguntas que se nos antoja formular: ¿se puede plantear una declinatoria de jurisdicción si el arbitraje se inicia acordada la suspensión de la cláusula ${ }^{85}$ ?; o ¿es de recibo pedir el

${ }^{82}$ Cuando la suspensión o la ineficacia de un convenio arbitral derivara del régimen concursal de un Estado situado fuera de la Unión, en donde se estuviera tramitando el concurso, y un tribunal judicial español tuviera que decidir sobre su competencia en relación con la disputa cubierta por el convenio. En este caso, el reconocimiento del procedimiento de insolvencia extranjero y de sus efectos en España estaría amparado por el art. 223 LC.

${ }^{83}$ la reforma de 2011 introduce una solución mucho más favorable para la vía arbitral. En efecto, según la actual redacción del art. $8.4^{\circ} \mathrm{LC}$, la jurisdicción del juez del concurso es exclusiva y excluyente en las siguientes materias:

"[.... 4. ${ }^{\circ}$ Toda medida cautelar que afecte al patrimonio del concursado excepto las que se adopten en los procesos que quedan excluidos de su jurisdicción en el párrafo $1 .^{\circ}$ de este precepto y, en su caso, de acuerdo con lo dispuesto en el artículo 52, las adoptadas por los árbitros en las actuaciones arbitrales, sin perjuicio de la competencia del juez para acordar la suspensión de las mismas, o solicitar su levantamiento, cuando considere que puedan suponer un perjuicio para la tramitación del concurso".

${ }^{84}$ El Acuerdo sobre la retirada del Reino Unido de Gran Bretaña e Irlanda del Norte de la Unión Europea y de la Comunidad Europea de la Energía Atómica (2019/C 384 I/01), incluye una serie de disposiciones que definen qué sucede con los procedimientos de cooperación judicial en curso durante el periodo transitorio y no finalizados el 31 de diciembre de 2020.

La cooperación judicial entre España y el Reino Unido se regirá con carácter general, en materia civil, por los Convenios internacionales adoptados en el marco de la Conferencia de la Haya de Derecho Internacional Privado.

${ }^{85}$ Un escollo con el que nos encontramos son los preceptos acogidos en la ley de arbitraje española, exactamente el art. 22.1 y el 11.2 en el sentido de que la declinatoria no impedirá la iniciación o prosecución de las actuaciones arbitrales. Reparemos 
reconocimiento y ejecución de la sentencia adoptando esa medida cautelar con la finalidad de paralizar el procedimiento de arbitraje?, ¿ procede someter la nulidad de la cláusula compromisoria al tribunal arbitral con motivo de la declinatoria?

111. Son muchos los interrogantes y muchas las respuestas a las que no procede dar cabida en este trabajo, pero en todo caso si dejar sentado, en aras a buscar la opción procesal más adecuada de las planteadas, que las normas de conflicto relativas a arbitraje que prevé el Reglamento de Insolvencia en los art. 7 y 18 son relevantes para todas las acciones de reconocimiento y ejecución presentadas ante las autoridades de cualquier Estado Miembro que se dirija contra una parte sometida a un pronunciamiento concursal en otro Estado de la Unión . La superioridad normativa del régimen del Reglamento y la necesidad de asegurar el effet utile de sus normas se deberá traducir en la prevalencia del instrumento europeo sobre las soluciones previstas en el art. V del CNY ${ }^{86}$.

112. Pese a que el Reino Unido ya no forma parte de la Unión Europea ello no nos supone un problema de partida, aunque si pudiera atraer otros, de calificación y conflictual, ya que a partir del 1 de enero de 2021, el acuerdo del Consejo sobre la retirada del Reino Unido ${ }^{87}$ una vez finalizado el periodo transitorio, el Reglamento (UE) 2015/848 del Parlamento Europeo y del Consejo, se aplicará a los procedimientos de insolvencia y a las acciones a que se refiere el artículo 6 , apartado 1 , de dicho Reglamento, siempre que el procedimiento principal se haya incoado antes del final del período transitorio $^{88}$, lo que ocurre en el asunto que nos ocupa, DelFuego Booking y David Guetta toda vez que hemos defendido que el Reglamento aludido atribuye competencia al juez concursal para adoptar la cautela de suspensión de los efectos del convenio arbitral.

113. En todo caso, asumiendo que no resulte de aplicación los instrumentos de la UE y, a salvo de los convenios multilaterales susceptibles de aplicación a ambos Estados, en materia de competencia judicial internacional, Convenio de Lugano de 2007 o de la Haya de 2005 sobre acuerdos de elección de foro o Convenio de 2 de julio de 2019 sobre Reconocimiento y ejecución de sentencias extranjeras en materia civil y mercanti1 ${ }^{89}$, se aplicará la normativa interna de derecho internacional que en nuestro caso está prevista en la Ley Concursal y/o LOPJ, lo que no supone cambio significativo alguno porque a la postre la primera de las leyes referidas siguió en su dictado las directrices pautadas por los Reglamentos de procedimientos de insolvencias analizados.

\section{Conclusiones}

114. La institución arbitral internacional y la insolvencia transfronteriza interaccionan y confluyen de manera cada vez más frecuente a tenor de la globalización imperante en la contratación. Es inevitable que el roce institucional provoque numerosas fricciones que se agudizan sobremanera por razones, entre otras muchas, de naturaleza, diseño y funcionamiento de ambas disciplinas.

115. Se avecinan malos tiempos para el mecanismo privado de resolución de controversias cuando una de las partes en el contrato deviene insolvente. La pandemia Covid-19 que estamos sufrien-

que la ley de arbitraje no solo hace aplicable su normativa a los arbitrajes nacionales e internacionales que se desarrollan en España (art. 1.1 LA) sino que prevé también la aplicación de algunos de sus preceptos a los arbitrajes que tengan lugar fuera del territorio español (es decir, combinan su normativa internacional con su carácter extranjero), art. 1.2 LA.

${ }^{86}$ M. Penedés Fons, op cit. pp. 397 y 398.

${ }^{87}$ Acuerdo sobre la retirada del Reino Unido de Gran Bretaña e Irlanda del Norte de la Unión Europea y de la Comunidad Europea de la Energía Atómica (2019/C 66 I/01) DOU 19 de febrero de 2019. Disponible: https://eur-lex.europa.eu/legal-content/ES/TXT/PDF/?uri=CELEX:12019W/TXT\&from=EN

${ }^{88}$ Art. 67.2 y 3 c) del Acuerdo del Consejo.

${ }^{89}$ Para profundizar en este tema vid. R. Arenas García, "Brexit y Espacio Europeo de libertad, seguridad y Justicia: de lo deseable a lo posible", Diálogos jurídicos 2018 Anuario de la Facultad de Derecho de la Universidad de Oviedo, pp. 28 y ss. 
do goza inexorablemente del elemento internacional lo que augura el siguiente escenario: que los operadores económicos, acuciados por sus acreedores, vayan en busca de una reestructuración de sus deudas al albor de la normativa protectora que rige en el ámbito transnacional, refugiándose en el procedimiento concursal y aprovechando la ocasión para solicitar la paralización de los efectos de los convenios arbitrales. Es en este momento cuando surge el problema para el juzgador pues la cuestión planteada, la relativa a la suspensión de una cláusula compromisoria como efecto de la declaración de concurso, es una cuestión de índole concursal y no arbitral.

116. Como quiera que la Convención sobre reconocimiento y ejecución de sentencias arbitrales extranjeras hecho en Nueva York el 10 de junio de 1958, así como el Convenio europeo sobre arbitraje internacional hecho en Ginebra el 21 de abril de 1961 no contienen norma alguna sobre los aspectos referidos a la búsqueda de la norma de conflicto y selección de ley aplicable, sin obviar que la materia concursal y el arbitraje están excluidos del ámbito de aplicación del Reglamento de Bruselas I Bis, hemos de centrar la atención en el Reglamento (UE) del Parlamento europeo y del Consejo sobre procedimientos de insolvencia 2015/ 848, de 20 de mayo de 2015, y encontrar en el la respuesta a todas las dudas sugeridas. Lo ideal sería lograr un método conflictual que sea operativo en el ámbito concursal como en el arbitral con la finalidad de que respete los principios y las peculiaridades de cada uno de ellos y a su vez un acuerdo en cuanto a la forma de calificación de la situación concursal a los efectos de la determinación de la ley aplicable.

117. El asunto objeto de tratamiento, la sentencia dictada en el incidente concursal denominado, DelFuego Booking y David Guetta, nos ha permitido crear una hoja de ruta actual que guíe aquellos supuestos en los que, declarado un concurso de acreedores en España, se solicita la suspensión de los efectos de la cláusula arbitral internacional que ha sido convenida por las partes pero que no ha provocado inicio de procedimiento alguno, y en la que uno de los suscriptores es la parte concursada.

118. El Reglamento 1246/2000 guardaba silencio acerca de los efectos del concurso sobre una clausula arbitral no activada a la fecha de declaración de la insolvencia, ni en sentido material ni de selección de ley aplicable, por lo que había de iniciarse una interpretación sistemática de su articulado en directa relación con el criterio Gourdain, y la naturaleza contractual y/ o procesal del Convenio arbitral. Fueron varios los asuntos que se tornaron emblemáticos y como punto de referencia inexcusable en la búsqueda de la norma de conflicto, en especial, asunto Elektrim y asunto Pirelli.

119. Ahora bien, eso no es suficiente, no es posible interpretar correctamente las normas sobre ley aplicable previstas por el Reglamento si no prestamos la atención que requiere el régimen de competencia judicial internacional y el principio de vis attractiva concursus diseñado por el legislador de la Unión. Únicamente tras explorar estos dos aspectos es posible proponer una interpretación apropiada de la influencia del Reglamento sobre el arbitraje internacional. Son muchas las acciones que se pueden ejercitar y derivarse del procedimiento de insolvencia o que guarden relación con ella y que están sometidas a las normas generales de competencia y reconocimiento y ejecución.

120. Con la entrada en vigor del Reglamento sobre procedimientos de insolvencia $2015 / 848$, de 20 de mayo de 2015, los parámetros de interpretación no son los mismos que los que fueron bajo el auspicio del Reglamento predecesor, pues la norma en vigor acoge un amplio criterio del principio de vis attractiva, así como una referencia expresa al arbitraje de los que carecía el anterior Reglamento, y lo que es sumamente importante, verdaderas normas de competencia judicial internacional, por lo que, acudir insistentemente en la actualidad a los asuntos Pirelli y Elektrim, no es del todo acertado, y en especial en el asunto DelFuego Booking y David Guetta, porque el nuevo reglamento se expresa con aceptable claridad.

121. Ya en el ámbito nacional, en el Estado de apertura del concurso, la norma que regula los efectos del procedimiento de insolvencia sobre los procedimientos arbitrales es el artículo 52 de la Ley 
Concursal que acoge un régimen distinto según nos encontremos ante un convenio arbitral o un procedimiento en tramitación, pero en todo caso, evidencia una posición pro convenio arbitral, criterio que se impuso a partir de la reforma 11/2011, de 20 de mayo.

122. Aunque el artículo $52.1 \mathrm{LC}$ se exprese claramente al referir que la declaración del concurso no afecta a los pactos de mediación ni a los convenios arbitrales suscritos por el concursado y que el juez, si entendiera que dichos pactos o convenios pudieran suponer un perjuicio para la tramitación del concurso, podrá acordar la suspensión de sus efectos, no evita que surjan generosas dudas, especialmente en lo referente a las posibilidades que tiene el juzgador cuando se encuentra ante una cláusula arbitral repleta de incertidumbres que puede ser susceptible de nulidad.

Esta situación obliga a hacer una interpretación de nuevo sobre aspectos relativos a la competencia y al procedimiento, así como a la concepción que nuestro ordenamiento tiene sobre el principio de la vis attractiva concursus y, en su caso, si la norma provoca un tratamiento diferente del arbitraje interno y del internacional. El resultado de la interpretación sistemática referida nos lleva a interesantes conclusiones que pasamos a exponer:

A) Que la norma de conflicto localizada por el juez concursal sea el Reglamento de procedimientos de insolvencia 2015/848 y que esta norma nos aboque a la aplicación de nuestra norma nacional, exactamente el artículo $52.1 \mathrm{LC}$, no ha de implicar necesariamente el destierro definitivo de la aplicación de los Convenios de Ginebra y de Nueva York, en cuanto que el precepto referido continúa en su dicción refiriendo que las posibilidades de suspensión por el juez lo es sin perjuicio de lo dispuesto en los tratados internacionales. No es esta última una alusión ni impertinente ni inútil como considera mayoritariamente la doctrina porque nos permite entender que el juez concursal no solo puede suspender los efectos de la cláusula compromisoria sino también valorar y acordar su posible nulidad, siempre que se den méritos para ello. Si ello no puede ser factible en vía principal, si puede serlo en la incidental, por lo que no se llega a colisionar con el principio Kompetenz-Kompetenz.

B) La suspensión de los efectos del convenio arbitral en sede concursal es una medida que comparte de la naturaleza de la cautelar, es decir, implica una paralización provisional de los efectos positivos y negativos de la cláusula compromisoria, lo que nos induce a pensar que la suspensión de los efectos no provoca una reactivación de las normas ordinarias de competencia judicial; lo que si permitiría, sin embargo, la declaración de nulidad de la cláusula cuando sea merecedora de tan radical efecto.

Entenderlo de otra manera implicaría obviar el espíritu de la reforma efectuada por la ley de arbitraje en el año 2011, y anular la cláusula cuando el precepto permite expresamente la suspensión de los efectos. En consecuencia, si se acuerda judicialmente la suspensión conllevaría una paralización de los efectos hasta que se proceda su alzamiento; si se acuerda la nulidad (a tenor de la aplicación de los tratados internacionales) una reactivación de las normas de competencia judicial. De no hacerlo así, nos encontraríamos ante una resolución incongruente con el dictado legal.

C) El perjuicio para la tramitación del concurso como condición de la suspensión de sus efectos está íntimamente relacionado con la concepción que se tenga de la suspensión de los efectos. Si entendemos que los efectos de la suspensión se asemejan a los de la nulidad de la cláusula y se declara esta, los perjuicios para el concurso y, por ende, para la masa activa, están servidos. En el asunto delFuego Booking y David Guetta analizamos críticamente que la declaración suspensiva de los efectos de la cláusula compromisoria permita acudir ante los tribunales, sino todo lo contrario. Es por todo ello por lo que abogamos por la no suspensión de los efectos de la cláusula compromisoria y con una clara finalidad, la de obtener un laudo arbitral favorable a las pretensiones de la concursada y con el activo obtenido poder reintegrar a los acreedores del concurso. 
El juez tiene una posibilidad más cuando se enfrenta a la pretensión de analizar la suspensión, también estaría legitimado para cuestionar la cláusula y su posible fraude, si hubiere méritos para ello, lo que también permitiría activar las normas de competencia judicial internacional y, por ende, la posibilidad de obtener una sentencia favorable al concursado.

La relación de posibilidades ofertadas al juzgador son coherentes con la obligación legal de velar por el interés del concurso y por el efecto útil del procedimiento colectivo y universal.

123. Como último apunte, la referencia que el artículo 52.1 in fine de la LC hace a los tratados internacionales tiene un segundo efecto útil, y mucho que ver con los efectos que la resolución suspensiva de los efectos de la cláusula compromisoria puede provocar ante los órganos jurisdiccionales y arbitrales de Estados comunitarios o no miembros de la UE. La razón no es otra que el retorno de nuevo a la internacionalización de la cuestión y a una nueva búsqueda de la norma de aplicación.

La problemática de los efectos extraterritoriales de los dictados judiciales y la respuesta que se vierta a cada una de ellas es sumamente importante pues en la efectividad de las resoluciones es en donde se halla la verdadera justicia material. 